Date paper written: Aug 17, 2012

\title{
COMPACTED SOIL BEHAVIOUR: INITIAL STATE, STRUCTURE AND CONSTITUTIVE MODELLING
}

Eduardo E. Alonso

Núria M. Pinyol

Antonio Gens

Corresponding author:
Professor of Geotechnical Engineering. Department of Geotechnical Engineering and Geosciences. Universitat Politècnica de Catalunya, Barcelona, Spain.

$\mathrm{PhD}$. International Center for Numerical Methods in Engineering (CIMNE) and Department of Geotechnical Engineering and Geosciences. Universitat Politècnica de Catalunya, Barcelona, Spain.

Professor of Geotechnical Engineering. Department of Geotechnical Engineering and Geosciences. Universitat Politècnica de Catalunya, Barcelona, Spain.

Eduardo E. Alonso

Department of Geotechnical Engineering and Geosciences.

Edificio D-2. Campus Nord. UPC. 08034 Barcelona

Phone: $\quad 34934016866 ; 34934017256$

Fax: $\quad 34934017251$

e-mail: _ eduardo.alonso@upc.edu 


\title{
COMPACTED SOIL BEHAVIOUR: INITIAL STATE, STRUCTURE AND CONSTITUTIVE MODELLING
}

\author{
E.E. Alonso, N.M. Pinyol \& A. Gens
}

Departament of Geotechnical Engineering \& Geosciences, UPC, Barcelona, Spain

\begin{abstract}
The paper explores the behaviour of compacted soils throughout the (dry densitywater content) compaction plane by means of a conceptual framework that incorporates microstructural information. Engineering properties of compacted soils are described by an initial state in terms of a yielding stress, soil suction and a microstructural parameter. Microstructure is
\end{abstract} defined by the ratio of microvoid volume to total void volume. The pattern of variation of the microstructural parameter within the compaction plane has been determined, for some compacted soils, by analyzing Mercury Intrusion Porosimetry data. Microstructure of wet and dry compaction

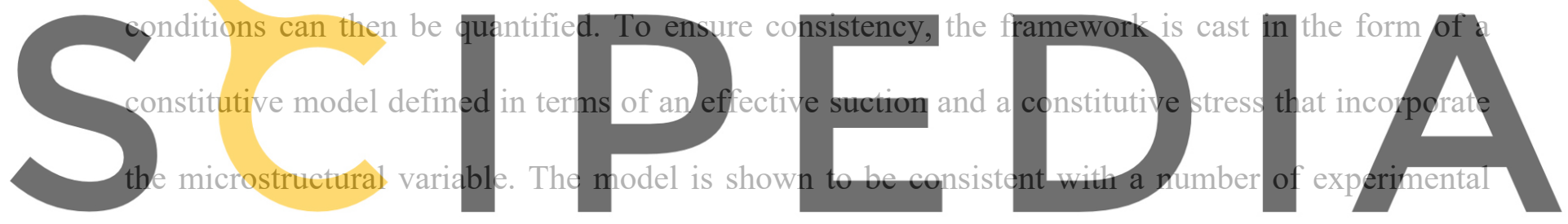

observations and, in particular, it explains the intrinsic collapse potential of compacted soils. It Register for free at https//www.scipedia.com to download the version without the watermark

predicts, for a common initial suction, a higher collapse potential for dry of optimum conditions if compared with wet compaction. It also predicts in a natural manner the observed evolution of soil compressibility during drained or undrained loading. Model capabilities are illustrated by application to a testing program on statically compacted samples of low plasticity silty clay. The compression behaviour of samples compacted wet and dry of optimum and the variation of collapse strains with confining stress have been successfully reproduced by the model.

KEYWORDS: Clays, Compaction, Constitutive relations, Fabric/structure of soils, Partial saturation, Plasticity, Suction 


\section{INTRODUCTION}

A significant proportion of the published research on unsaturated soil mechanics concerns compacted soils. It could be inferred that examining the current state of development of unsaturated soil research would provide detailed information on compacted soil behaviour. This is only partially true, however. Often, basic research is conducted in silty materials, statically compacted at a low density. These soils exhibit an open structure sensitive to suction-induced effects. Compacted soils in practice span a much wider range of grain size distributions. Proctor (1933) was able to show the fundamental relationship between attained density and water content for a given compaction energy. This finding defined the compaction plane (in terms of dry unit weight, $\gamma_{d}$, vs. water content, $w$ ) which is a very convenient procedure to represent compaction states of a given soil. This plane remains the basic representation for investigating the properties of compacted soils.

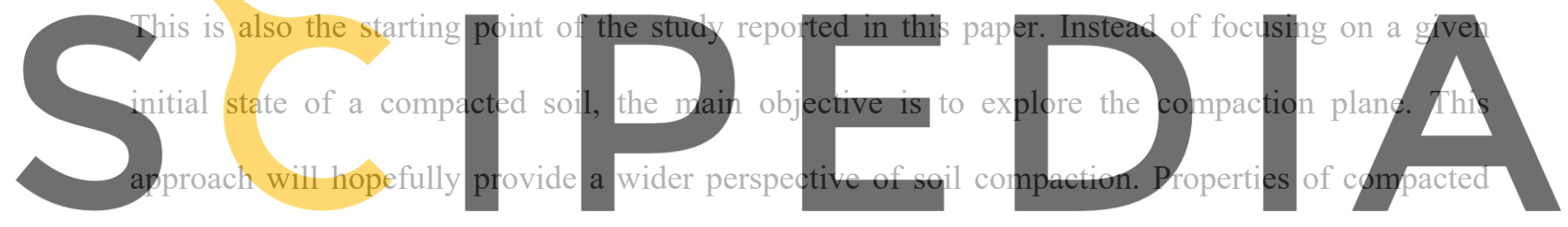

soils (permeability, stiffness, strength) were linked to the compaction state in a number of classical Register for free at https//www.scipedia.com to download the version without the watermark contributions published in the 50's and 60's (Lambe, 1958; Lambe and Whitman, 1969; Leonards,

1955; Seed and Chan, 1959). This idea is recovered here, but the focus now is to incorporate advances in unsaturated soil mechanics reported in the last two decades. Significant recent contributions involve the search for appropriate constitutive stress formulations, the development of elastoplastic frameworks and the increasing recognition of the role played by soil microstructure.

Microstructure, in particular, was very early identified as a key feature in any explanation of compacted soil behaviour associating dispersed microstructure with compaction on the wet side (wetter than optimum) and flocculated microstructure with compaction on the dry side (drier than optimum) (Lambe 1958; Lambe and Whitman, 1969). However, direct observations of soil fabric by means of scanning electron microscopy and the interpretation of mercury intrusion porosimetry 
tests reported from the 70's (Sridharan et al., 1971; McGown and Collins, 1975) led to significant changes of this initial microstructural interpretation. It was observed, for instance, that clay tended to form aggregated structures that behaved as much larger particles, especially when compacted on the dry side. It was soon accepted that water was trapped inside the clay aggregations, even if the mixture remains relatively dry. These ideas have been widely confirmed by subsequent studies (Delage et al., 1996; Romero \& Simms, 2008; Lee \& Zhang, 2009; Monroy et al., 2010).

The debate on effective stress has been a recurrent topic in unsaturated soil mechanics research since the early introduction by Bishop (1959) of an effective stress equation. This topic will be discussed further below. The unavoidable fact is, however, that modern constitutive laws for unsaturated soils that attempt to provide a comprehensive description of soil behaviour (and not just of a specific property) have been always formulated in terms of two "stress states" or "constitutive

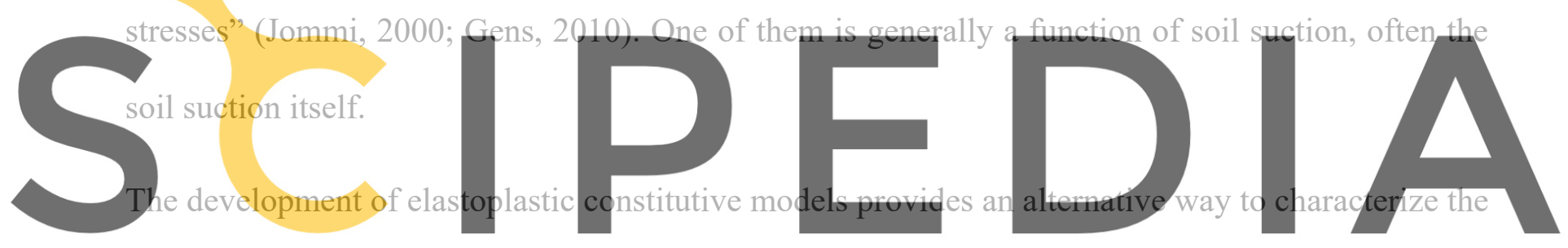

initial state of compacted soils by associating model parameters and variables with the pair dry unit Register for free at https//www.scipedia.com to download the version without the watermark

weight and water content $\left(\gamma_{d}, w\right)$ that defines the 'as-compacted' condition. For instance, the

attained dry density achieved by compaction can be related to the position of the initial yield surface after compaction. Water content, on the other hand, is mainly controlled by the current suction, $s$, and to a lesser extent by the void ratio. In the context of the simple elastoplastic BBM model (Alonso et al., 1990), the yield surface is essentially defined by the isotropic yield stress for saturated conditions, $p_{0}^{*}$. Therefore, as a starting point, the pair $\left(p_{0}^{*}, s\right)$ may provide equivalent information to $\left(\gamma_{d}, w\right)$ with one added advantage: they supply fundamental information for constitutive modelling.

An analysis of a limited number of soil compaction testing programs led to the $p_{0}^{*}\left(\gamma_{d}\right)$ relationship given in Figure 1 (Alonso \& Pinyol, 2008). It can be noted that the saturated isotropic yield stress 
increases rapidly with dry density. Also, for a given dry density, the yield stress $p_{0}^{*}$ increases significantly with soil plasticity. The plot in Figure 1 may help to select $p_{0}^{*}$ in the absence of specific tests. On the other hand, many $s\left(w, \gamma_{d}\right)$ relationships can be found in the literature (e.g. Gens et al., 1995; Li, 1995; Romero et al., 1999; Tarantino and Tombolato, 2005).

Thus, the pair $\left(p_{0}^{*}, s\right)_{\text {as compacted }}$, provides key information concerning the compacted state of a given soil, but it does not include any information on its microstructure. A review of microstructural effects on the compacted soil behaviour given below indicates that microstructure is also a significant aspect that should be introduced in a realistic modelling of compacted soils. The generalisation of techniques (particularly mercury intrusion porosimetry, MIP) to examine the evolution of soil microstructure has provided information regarding the effects of microstructure on engineering behaviour of compacted soils. The incorporation of such effects is a key aspect of the work presented here.
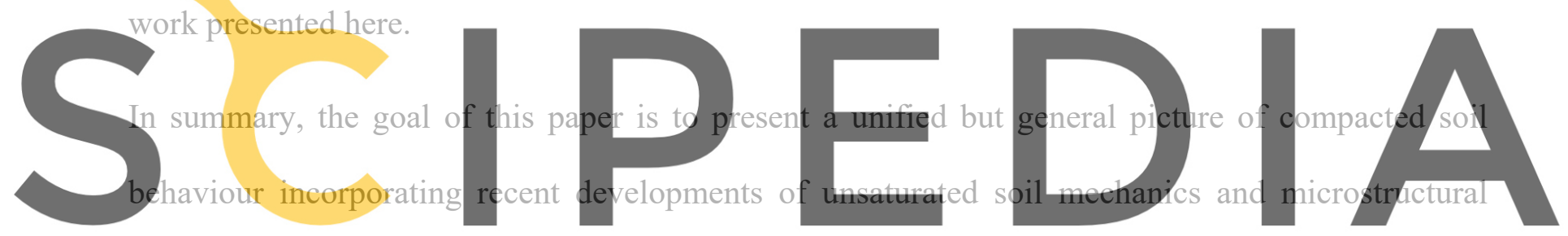

considerations.

Register for free at https//www.scipedia.com to download the version without the watermark

The paper is organised as follows. First, a summary of some relevant experimental work devoted to isolate the effect of microstructure on compacted soil behaviour is presented. Then, a constitutive stress expression that incorporates explicitly soil microstructure is introduced. This is done through the definition of a single microstructural state variable. The interpretation of a number of testing programs providing data on pore-size distribution has allowed mapping this microstructural state variable onto the compaction plane and the establishment of general trends of behaviour. Compressibility and its relationship with suction and microstructure are then discussed, because it leads to a consistent description of collapse behaviour, one of the key aspects of unsaturated soil behaviour. To ensure consistency, the description of behaviour is cast in the form of a new 
constitutive framework that incorporates the developments and concepts described previously. Its predictive capabilities are checked against experiments.

\section{MICROSTRUCTURE AND COMPACTED SOIL BEHAVIOUR}

In this paper, information on microstructure is derived from MIP tests performed both after compaction and after the application of a given stress-suction path.

Consider, in Figure 2, the pore size density function of a sample of low plasticity Barcelona silty clay $\left(w_{L}=28 \%, I P=9.3 \%\right)$ statically compacted at a high void ratio $(e=0.82)$ and then isotropically loaded in a triaxial cell to a substantially lower void ratio ( $e=0.57$ ) (Buenfil et al, 2004). The observation of two dominant pore sizes during compaction, especially dry of optimum, is a characteristic feature, widely observed. We will refer to these two dominant pore sizes as micro

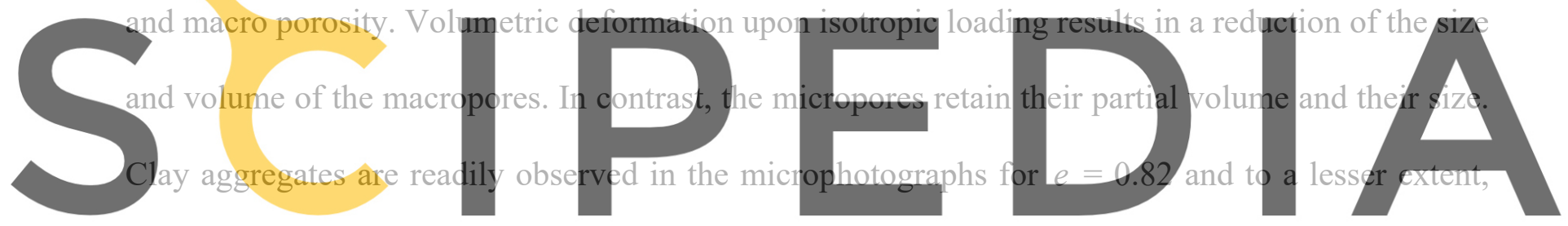

for $e=0.57$ where it can be observed that the size of the macropores has clearly reduced.

Register for free at https//www.scipedia.com to download the version without the watermark

A second example of the effect of loading and suction changes is given in Figure 3 for Boom clay

initially compacted to $e=0.93$ and $S_{r}=0.44$ (Romero et al., 2011). The specimen was wetted at constant volume (swelling pressure path) and then dried at constant vertical stress in an oedometer cell. The stress-suction path applied is sketched in Figure 3a. Pore size distribution tests were performed at points 1, 2 and 3 and the results are given in Figure $3 \mathrm{~b}$. The first loading-wetting path results in a significant reduction in the size of macropores. Further drying reduced the volume of macropores. Yet, microporosity seems to remain largely unchanged throughout.

Figure 4 shows the change in pore size distribution of a sample of Barcelona silty clay, statically compacted on the dry side (Sample DD), when it is wetted under a small confining stress and taken 
to the position DW close to saturation conditions. Some changes are observed but, in this case, the "as compacted" pore size distribution seems to be largely preserved after wetting.

This is consistent with the results of Thom et al. (2007) testing statically compacted kaolin, dry of optimum, who indicated that the bimodal domain of voids induced by soil compaction is essentially maintained upon application of significant stress and suction changes. However, this is not always the case. Wetting tests reported by Monroy et al. (2010) on statically compacted high plasticity London clay indicate that changes in micropores may also be significant on wetting. The higher activity of the clay probably explains the enhanced sensitivity of microporosity to suction changes.

The variation of engineering properties of a given soil when compacted at different dry densities and water contents has been often reported (Cox, 1978; Lawton et al., 1989, 1991; Alonso et al., 1992; Benson et al., 1992; Reséndiz, 1980; Fredlund and Rahardjo, 1993; Tinjum et al., 1997;
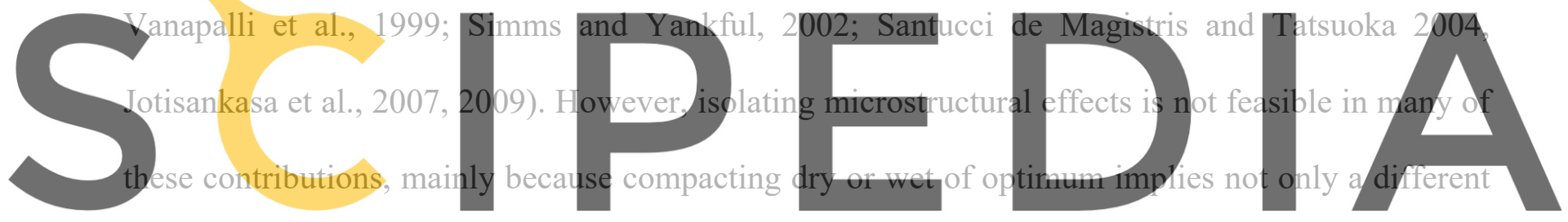

microstructure, but also a different suction. In addition, compacting at different void ratios implies Register for free at https//www.scipedia.com to download the version without the watermark

both a variation in macroporosity and a change in the initial yield locus. Hence, conventional testing

of compacted samples mixes the effects of the initial state $\left(p_{0}^{*}, s\right)$ and of the microstructure. Therefore, specifically-designed testing programmes are required to isolate microstructural effects.

An interesting example of such programmes is provided by Santucci de Magistris \& Tatsuoka (2004), who tested dynamically compacted specimens of low plasticity silty sand (a residual granitic soil) in a triaxial cell. Once compacted, all samples were taken to a saturated state before testing. Being a low plasticity soil it is expected that the as-compacted microstructure was essentially preserved and, naturally, suction at the testing stage was zero. They found that the slope of the virgin compression line changes moderately with moulding water content from wet to dry conditions, except for states in the vicinity of the Modified Proctor Optimum. Similar conclusions 
were reached concerning small strain stiffness. Drained strength (the limiting $q / p^{\prime}$ ratio) was not much affected by the attained dry density although dry compaction resulted in a moderate increase in dilatancy when compared with wet compaction.

Wheeler \& Sivakumar $(1995,2000)$ testing statically compacted speswhite kaolin found that the slope and intercept of normal compression lines for constant suction depend on compaction water content and compaction stress. A similar result was found for the volumetric critical state line.

Microstructural effects may be directly identified if specimens having a different origin (say compacted dry and wet of optimum) are tested at a common state. Instead of selecting a saturated state, Suriol et al. (1998) and Suriol and Lloret (2007) tested samples of statically compacted Barcelona silty clay $\left(w_{L}=30.5 \%\right.$ and $\left.I P=11.8 \%\right)$ in a suction-controlled oedometer cell. The approach adopted is illustrated in Figure 5a. Under a vertical compaction stress of $0.6 \mathrm{MPa}$, and a

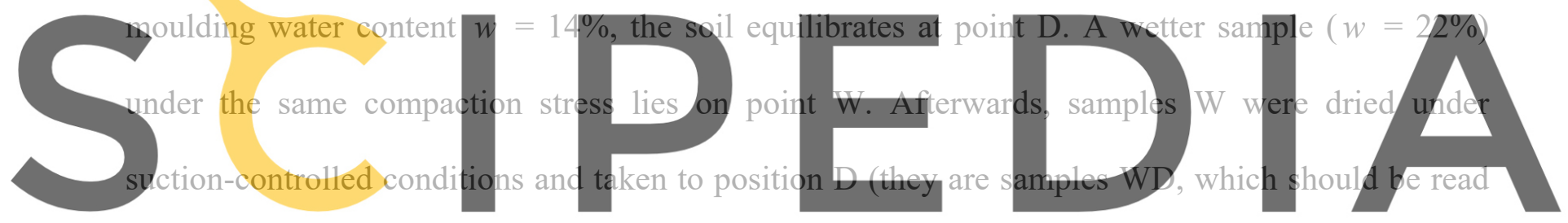

as "compacted in position W and tested in position D"). In contrast, samples DD are both Register for free at https//www.scipedia.com to download the version without the watermark compacted and tested in D. The pore size distributions of samples DD and WD are given in Figure

5b. Samples DD exhibit a marked double porosity. Samples WD have developed a dominant intermediate pore size.

Samples DD and WD were then loaded in a suction-controlled oedometer maintaining the suction prevailing at point $\mathrm{D}(1 \mathrm{MPa})$ and then saturating the specimens under constant vertical stress. The measured vertical strains (collapse strains) are plotted in Figure 5c in terms of applied vertical stress. DD specimens collapse more than WD samples, a clear indication of the effects of microstructure since dry density, water content and suction are the same in the two cases.

The effect of microstructure on elastic stiffness and strength will be further discussed once the constitutive stress is defined. However, a final property is discussed here: permeability. As this 
parameter is essentially controlled by the pore structure of the soil, it provides a good indication of microstructural changes if permeability of samples compacted at different $\left(\gamma_{d}, w\right)$ values are measured under saturated conditions. Again, this is especially true if microstructural changes during the saturation process are minor. Figure 6 reproduces results published by Mitchell et al. (1965). The soil, a silty clay, was compacted by kneading action. Contours of equal saturated permeability are plotted in the compaction plane. Clearly, permeability is not uniquely controlled by void ratio. In fact, a strong variation is observed when, for a given void ratio compaction water content increases. Thus, permeability reveals much better than mechanical tests, microstructural effects.

The plot in Figure 6 indicates that designs involving compacted soils in which permeability is an important issue (e.g. isolating barriers) cannot be based only on classical criteria limiting dry density and water content on the basis of mechanical tests. Adding microstructure in some manner to the constitutive behaviour of compacted soils would help to incorporate hydraulic properties of
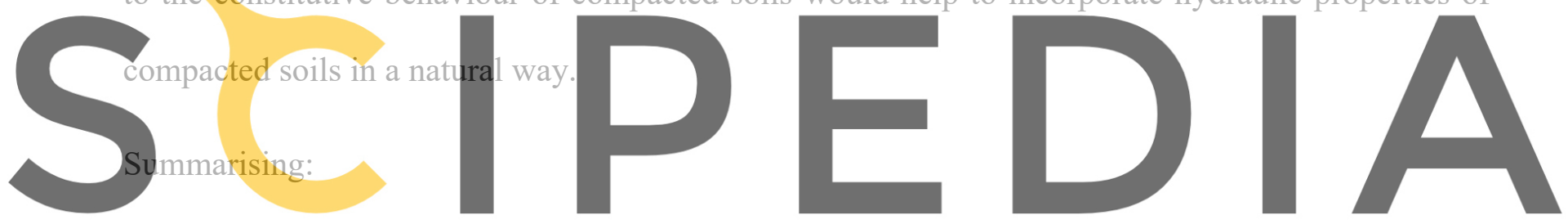

It is clear that microstructure of compacted soils has a distinct effect on their geotechnical Register for free at https//www.scipedia.com to download the version without the watermark properties not accounted for only by the stress pair $\left(p_{0}^{*}, s\right)$.

- Not all the properties are equally sensitive to microstructure. One extreme case is probably the soil permeability. On the opposite side, drained strength parameters do not seem to be much affected.

- Compressibility and, therefore, collapse and swelling potential are controlled to a significant extent by microstructure.

- Stress and suction paths applied to compacted specimens mainly modify the macroporosity but in active soils (high plasticity clays) changes associated with suction variations may also modify the microstructural void volume. 


\section{EFFECTIVE DEGREE OF SATURATION AND CONSTITUTIVE STRESS}

A full description of the pore structure of a soil would require a large number of parameters preventing the incorporation of such information into a simple constitutive formulation. Here, the pore size distribution is described by a simple state variable: the ratio of the microstructural void ratio, $e_{m}$, and the total void ratio, $e$. This ratio will be known here as the microstructural state variable:

$$
\xi_{m}=e_{m} / e
$$

If water has access to an initially compacted dry soil it is expected that the microstructure will saturate first because of the strong affinity for water of the clay platelets. Once the microvoids inside clay aggregates are saturated, any excess of water will occupy the macropores. Alonso et al.

(2010) suggested that only the water partially filling the macropores will have a significant

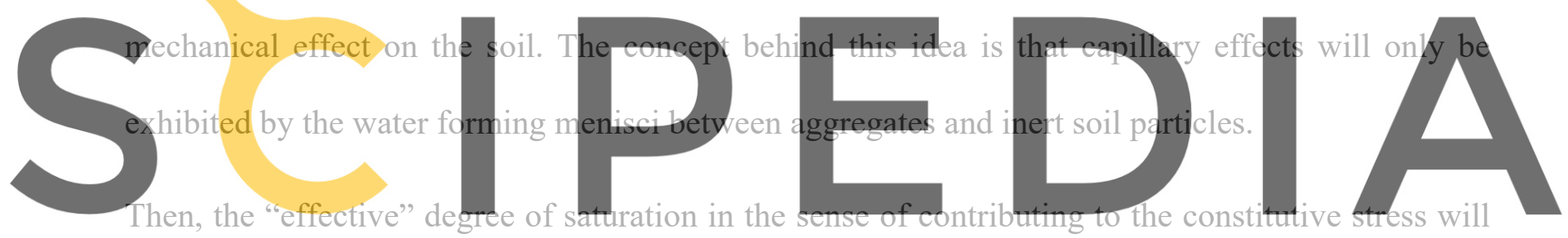

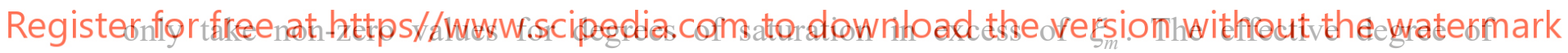

saturation was assumed to vary between 0 and 1 , when $S_{r}$ spans the macropore space $\left(\xi_{m} \leq S_{r} \leq 1\right)$.

This is illustrated in Figure 7 for the particular value $\xi_{m}=0.4$. Sketches showing the assumed distribution of water in the micro and macro volumes illustrates the location of the water as the degree of saturation increases. The effective degree of saturation is given by the equations:

$$
\begin{aligned}
& \bar{S}_{r}=\frac{S_{r}-\xi_{m}}{1-\xi_{m}} \text { for } S_{r}>\xi_{m} \\
& \bar{S}_{r}=0 \text { for } \quad S_{r} \leq \xi_{m}
\end{aligned}
$$

The expression (2a) for the effective degree of saturation was already introduced by Romero and Vaunat (2000) and Tarantino and Tombolato (2005).

It is proposed to define unsaturated soil behaviour in terms of two independent stress fields: 
Constitutive stress: $\bar{\sigma}=\sigma-p_{g}+\bar{S}_{r} s$

Effective suction: $\bar{s}=\bar{S}_{r} s$

where the effective suction and the constitutive stress have been made dependent on void ratio, microstructural void ratio and degree of saturation by means of the effective degree of saturation. In equation (3a) $\sigma$ is the total stress and $p_{g}$ the gas pressure.

Partial aspects (elastic stiffness, drained failure envelopes) of unsaturated soil behaviour were shown to be well predicted by interpreting results in terms of Equation (3a) (Alonso et al., 2010).

The piecewise expression (2) was smoothed in Alonso et al. (2010) by a continuous power law $\left(\bar{S}_{r}=\left(S_{r}\right)^{\alpha} ; \alpha>1\right)$ which provides some advantages in calculations. However, the power function loses a direct reference to the microstructural state variable, $\xi_{m}$, which is a variable capable of being experimentally measured in MIP tests as described in the next section.

Following the procedure put forward by Gesto et al. (2011), an alternative smoothing of $\bar{S}_{r}$ around the corner $S_{r}=\xi_{m}$ that maintains $\xi_{m}$ as a material state variable can be achieved by the equation

$$
\bar{S}_{r}=\frac{S_{r}-\xi_{m}}{1-\xi_{m}}+\frac{1}{n} \ln \left[1+\exp \left(-n_{\text {smooth }} \frac{S_{r}-\xi_{m}}{1-\xi_{m}}\right)\right]
$$

The number $n_{\text {smooth }}$ defines the degree of smoothing around the corner (Fig. 8). It can be noted that Equation (4) provides a small effective stress contribution for $S_{r}<\xi_{m}$ which is likely to be more realistic than the sharp transition shown in Figure 7.

\section{MAPPING MICROSTRUCTURE ON THE COMPACTION PLANE}

The microstructural state variable $\xi_{m}$ was shown by Alonso et al. (2010) to increase with soil plasticity. However, no indication of the effect of varying compaction variables was given. A recently conducted experimental program has explored in a systematic manner the microstructure of 
compacted Boom clay (Merchán, 2011). The attained dry densities covered a wide range (1.40 $1.85 \mathrm{~g} / \mathrm{cm}^{3}$ ), spanning the values typical of practical engineering applications. Figure 9 shows the position of samples tested in the compaction plane. MIP tests in which mercury was first intruded and then extruded after reaching a maximum pressure of $227 \mathrm{MPa}$ were conducted on all samples.

There are alternative procedures available to determine the macro and micro pore volumes. If only the intrusion curve is analysed, the density distribution of pore sizes may be interpreted in a straightforward manner by calculating the areas corresponding to the two porosity levels. The density function provides the information to establish the macro-micro pore size boundary. However, this procedure becomes difficult to apply if the distinct bimodal shape is lost.

If the extrusion cumulative curve is available, Delage \& Lefebvre (1984) suggested an alternative procedure to distinguish between porosity levels, as sketched in Figure 10. Microporosity was judged to result in a reversible (elastic) volume of mercury intruded and extruded from the small voids. In contrast, mercury would be trapped in the macropores by capillary effects once the applied pressure is removed. This concept and the resulting procedure to determine the micro and macroporosities are adopted here for two reasons. Firstly, it results in a non-ambiguous procedure to identify the two porosities. Secondly, the idea of a reversible behaviour of the volume change induced by pore pressures changes in the microporosity (also identified as the intra aggregate space) is consistent with the behaviour of interacting clay platelets. This issue was further discussed by Gens \& Alonso (1992). In fact, the double structure model proposed there to describe the behaviour of expansive clays highlights the reversible behaviour of the microstructure of clayey soils.

Using the Delage \& Lefebvre (1984) procedure to identify macro and microporosity, the microstructural state variable was determined for all the samples shown in Figure 9. Figure 11 shows the variation of the microstructural void ratio in the compaction plane. Interpolated contours show that $e_{m}$ is essentially controlled by the compaction water content. 
Derived values of state variable $\xi_{m}$ are indicated in Figure 12 for all the compacted specimens tested. Contours of equal $\xi_{m}$ are also plotted. The data shows an increase of $\xi_{m}$ with density that reflects the progressive reduction in void ratio. Equally relevant is the effect of compaction water content. For a given void ratio, $\xi_{m}$ increases with compaction water content reflecting the fact that samples compacted wet develop a larger amount of micropores.

To illustrate the effect of compaction conditions, consider, for instance, two specimens essentially compacted to the same dry density and different water contents: M9 (a drier specimen) and M3 (a wetter specimen). Their microstructural states ( $\xi=0.4$ for $\mathrm{M} 9$ and $\xi=0.6$ for $\mathrm{M} 3$ ) and the implication in terms of effective degree of saturation are shown in Figure 13. If both samples are partially filled with water to a common degree of saturation (say $S_{r}=0.8$ ), their different microstructures will result in specimen M9 (drier) exhibiting a higher effective degree of saturation than M3. Therefore, under a common suction, M9 will experience a higher constitutive stress than specimen M3.

Other recently published data on MIP intrusion-extrusion measurements of compacted specimens support the general trend of $\xi_{m}$ variation observed in Figure 12. This is the case presented in Figure 14, that collects data reported by Romero et al. (2011) on statically compacted Boom clay. Tarantino \& de Col (2008) published MIP data on a few statically compacted samples of kaolin. The calculation of $\xi_{m}$ has also been based on the intrusion-extrusion diagram of MIP tests. The figure shows the compaction curves for increasing vertical compaction stress, the contours of equal degree of saturation, the calculated values of $\xi_{m}$ for the few samples tested and the contours for equal $\xi_{m}$. The three plots (Fig. 12, 14 and 15), which correspond to two different soils and three independent testing programs show similar trends.

In order to demonstrate that these conceptual ideas can be integrated in a consistent manner, a constitutive model compacted soil behaviour has been developed that includes microstructural 
information in terms of the parameter $\xi_{m}$. The first step is an analysis of compressibility, described in the next section.

\section{A CONSTITUTIVE MODEL INCORPORATING MICROSTRUCTURAL EFFECTS}

The constitutive stress defined in Equation (3a) was capable of predicting strength and elastic stiffness in unsaturated states if these properties are known for a saturated state (Alonso et al., 2010). This partial success is however far from implying that the constitutive stress thus defined can predict consistently the volumetric behaviour of wet and dry compacted samples against stress and suction changes. Specifically, thinking in terms of different compaction conditions, the challenge is to investigate if the volumetric behaviour of compacted samples can be predicted by considering only the initial stress state (say, $p_{0}^{*}$ and $s$ ) and a microstructural state variable such as $\xi_{m}$. The differences in collapse behaviour shown in Figure 5 that are basically controlled by microstructure provide an important benchmark to check the above hypothesis.

A convenient starting point towards this goal is to review the compressibility of samples compacted dry and wet of optimum and to interpret them in terms of effective suction. In fact, compressibility has already been shown to depend on prevailing suction (Alonso et al., 1987, 1990; Wheeler \& Sivakumar, 1995). If microstructure affects compressibility as well, the relationship between a compression coefficient and suction will also depend on the compaction water content (for a common initial void ratio). However, as the effective suction defined above incorporates microstructural effects, it is possible that a unique relationship between compressibility and effective suction may emerge.

\subsection{Model formulation for isotropic stress states}

The model is defined in terms of two variables: the constitutive stress defined in Equation (3a) and the effective suction defined in Equation (3b). Changes in the constitutive stress induce elastic and elastoplastic strains, respectively, according to the following logarithmic relationships: 
$d e^{e}=-\bar{\kappa} \frac{d \bar{p}}{\bar{p}}$

$d e^{e p}=-\left.\bar{\lambda} \frac{d \bar{p}}{\bar{p}}\right|_{\bar{s}=\text { constant }}$

which introduce the definition of compressibility coefficients against changes in constitutive stress. The elastic index, $\bar{\kappa}$, is assumed to be constant in this paper.

It is accepted, in view of previous results, that $\bar{\lambda}$ is a function of the effective suction:

$$
\frac{\bar{\lambda}(\bar{s})}{\lambda(0)}=f(\bar{s})=f\left(\bar{S}_{r} s\right)
$$

where $\bar{S}_{r}$ is defined in Equation (4). Compression lines assumed by this model are plotted in Figure 16 in terms of the constitutive stress, for different effective suctions.

Parameter $\bar{\lambda}$ is conceptually very different from the "standard" compressibility coefficient, $\lambda$, defined in terms of net stress. In order to estimate $\bar{\lambda}$, the variation of void ratio with constitutive stress at constant effective suction is required. Suction controlled tests do not provide directly such information, even if the microstructural void ratio is known and assumed to be constant, because void ratio is changing during loading and effective suction is thereby varying continuously. During loading $e$ reduces and $\xi_{m}=e_{m} / e$ increases. The effect of this increase is illustrated in Figure 17. If the degree of saturation is maintained during loading (this is approximately the case of constant suction loading) the effective degree of saturation and, therefore, the effective suction will decrease (Fig. 17a). As a result, the coefficient $\bar{\lambda}$ will also decrease during loading. The effect of this continuous decrease of $\bar{S}_{r} s$ during loading is illustrated in Figure 18: the actual compression curve "travels" during loading across the compression lines plotted at constant effective suction $\left(\bar{S}_{r} s\right)$ values. This is also the case for undrained loading (constant water content) for a double reason: the reduction in void ratio and the associated decrease in suction. The net result is that, during undrained loading, void ratio decreases faster in terms of effective stress. If the degree of saturation changes also with void ratio (thinking in a suction controlled test, for instance) an additional change 
in effective degree of saturation and constitutive stress is introduced. Therefore, $\bar{\lambda}$ cannot be readily estimated from "standard" laboratory compression curves relating void ratio and net stress.

Despite these difficulties, the definition of elastoplastic compressibility in Equation (7) leads to a powerful and simple model to predict the isotropic compression of unsaturated soils for a wide range of applied stresses. It reconciles existing formulations based either on a decrease (as in BBM, Alonso et al., 1990) or an increase (Wheeler and Sivakumar, 1995) of compressibility with suction and predicts in a natural way the evolution of collapse strains with suction, which exhibits a maximum for some intermediate confining stress. This is discussed again below.

Further analysis requires the proposal of a particular relationship for the function $f(\bar{s})$ in Equation (8). A difficulty of making $\bar{\lambda}$ depending on effective suction is that compressibility would change when the soil is saturated and subjected to suctions lower than the air entry value. To avoid this shortcoming, the following equation is proposed for $\bar{\lambda}$ in terms of the effective suction:

$$
\frac{\bar{\lambda}(\bar{s})}{\lambda(0)}=\bar{r}+(1-\bar{r})\left[1-\left(\frac{\bar{s}}{\bar{s}_{\lambda}}\right)^{1 /(1-\bar{\beta})}\right]^{-\bar{\beta}}
$$

where $\bar{r}, \bar{\beta}$ and $\bar{s}_{\lambda}$ are material parameters. Equation (9) is plotted in Figure 19 for different values of $\bar{r}, \bar{\beta}$ and $\bar{s}_{\lambda}$. Parameter $\bar{\beta}$ controls the rate of variation of $\bar{\lambda}(\bar{s}) / \lambda(0)$ with effective suction between two limits ( 1 and $\bar{r}$ ). Parameter $\bar{r}$ defines the maximum stiffness of the soil as effective suction increases $(\bar{r} \lambda(0))$. Suction $\bar{s}_{\lambda}$ defines the air entry value. In fact, it can be taken as being the equivalent parameter of the Van Genuchten (1980) expression for the water retention relationship. Note in Figure 19 that $\bar{\lambda}$ is essentially constant when the effective suction is smaller than $\bar{s}_{\lambda}$. Within this range of suctions, effective suction and suction are essentially equal.

The effective yield isotropic stress for unsaturated conditions $\left(\bar{p}_{0}\right)$ is defined by the following Loading Collapse (LC) yield curve:

$$
\frac{\bar{p}_{0}}{\bar{p}_{c}}=\left(\frac{p_{0}^{*}}{\bar{p}_{c}}\right)^{\frac{\lambda(0)-\kappa}{\bar{\lambda}(\bar{s})-\kappa}}
$$


where $\bar{p}_{c}$ is a reference mean effective stress corresponding to the point where virgin compression lines for different effective suctions cross. Since the preconsolidation stress depends on the effective suction, samples compacted at the same void ratio but having different microstructural parameters will exhibit different LC loci. Equation (9) is a unique expression for the entire compaction plane. Differences in compressibility will be the result of differences in current values of suction and microstructural state variable, $\xi_{m}$.

In order to provide an insight into the performance of the compression model defined, a synthetic example is presented. Several isotropic compression tests, run at different values of suction, which remain constant during loading, are simulated. Model parameters are listed in Table 1. The dependence generally observed of water retention with void ration $(e)$ has been introduced in the model in a simple way by expressing parameter $P_{0}$ of the Van Genuchten model as a linear function of $e$ (Table 1). The model is explored for two "samples" of the same soil compacted on the dry (sample SI-D) or wet (sample SI-W) side. It can be noted that the same set of parameters are used for the two specimens, the only difference being the value of the initial microstructural state variable, $\xi_{m 0}$.

Model calculations are shown in terms of two sets of stress variables: constitutive stress and effective suction in Figure 20 and net stress and suction in Figure 21. The plots of volumetric strain against constitutive stress (Fig. 20) show the change in soil compressibility with applied stress, discussed above. Points corresponding to a particular value of effective suction may be identified on each compression curve and they are indicated in the figures. Straight lines connecting these points define the compressibility coefficient $\bar{\lambda}$ of the underlying model.

The compression curves in Figure 20 may be represented also in terms of volumetric strain vs. net stress and suction (Fig. 21). This plot shows the compression lines that would be directly recorded in conventional isotropic tests at constant suction. The model predicts that those "standard" compression lines of an unsaturated soil will first respond in a stiff manner, compared with the 
saturated compression line. But as deformation (and suction changes) accumulates, the compressibility index will eventually become similar to $\lambda(0)$ and then it will reach higher values in order to decrease again later when the saturated compression line is approached asymptotically. In loose soils, the first stage is often not observed and the measured apparent compression index for a given suction exceeds the saturated value (this was the case presented by Wheeler $\&$ Sivakumar, 1995). In dense soils, the entire transition from $\lambda<\lambda(0)$ to $\lambda>\lambda(0)$ is observed, provided the applied stress is large enough. This type of result was shown, for instance, by Romero (2002) testing compacted Boom clay in a suction-controlled oedometer, by Jotisankasa et al. (2007) testing a compacted mixture of silt, kaolin and London clay, and by Benatti et al. (2011) testing a colluvial collapsible silty clay.

To move from Figure 21 to 20 requires knowing the degree of saturation during loading and information on the initial microstructural state variable in order to identify the variation of $\bar{\lambda}$ with effective suction through the compression lines. Two or more tests, providing the measurement of void ratio, suction and degree of saturation during compression, are required to obtain this variation and to determine the parameters in Equation (9).

The shape of the compression lines in Figures 20 and 21 indicate that the model is capable of simulating collapse strains that first increase with confining stress and then reduce, as frequently observed in collapse tests. Sometimes the final reduction in collapse is not observed because the applied stress is not high enough; in this case, collapse seems to be an increasing function of applied stress. This is the prediction of BBM. This issue is also discussed by Sheng (2010) and Zhou et al. $(2012 a, b)$ in the context of a model in which the plastic compressibility index depends on the degree of saturation. Their model also predicts collapse strains first increasing and then decreasing with applied confining stress.

Comparison of Figures $21 \mathrm{a}$ and $21 \mathrm{~b}$ (or 22a and 22b) provides finally the effect of soil microstructure introduced by dry and wet compaction. Dry compaction, characterized by a lower 
initial microstructural state variable $\left(\xi_{m 0}\right)$, results in a stiffer soil response than wet compaction. In addition, collapse strains, for any confining stress, are higher for dry compaction. This result was also measured in the real tests that are described below.

\subsection{Simulation of tests on compacted Barcelona silty clay}

Consider again the DD and WD tests series on compacted Barcelona clay reported by Suriol and Lloret (2007) (Figs. 4 and 5). Microstructure of samples WD and DD was discussed on the basis of the intrusion curve only. The pore size density plot reproduced in Figure $5 b$ was in fact the derivative of the accumulated mercury volume during the pressure increase phase of the test. Although not reported, the authors also recorded a extrusion (pressure decrease) branch. They are shown in Figure 22 for the DD and WD samples. The available extrusion curves, performed on several samples compacted to the same initial state to check repeatability of results, did not reach a zero rate of volume change but they were close. The plots allow the calculation of the microstructural void ratio as suggested in Figure 10. The following as compacted (initial) values are derived for $e_{m 0}$ and $\xi_{m 0}$ : Sample DD : $e_{m 0}=0.19 ; \xi_{m 0}=0.36$; sample WD : $e_{m 0}=0.22 ; \xi_{m 0}=0.41$. These values are consistent with the trends shown in Figures 12, 14 and 15: Wet of optimum compaction results in higher microstructural void ratio.

Collapse tests represented in Figure 5c for the WD and DD samples were limited to vertical stresses not exceeding $2 \mathrm{MPa}$. However, additional oedometer tests for samples WD and DD were performed later in a high capacity loading frame and the vertical confining stress reached a maximum value of $8 \mathrm{MPa}$. The measured collapse strains for the full $0-8 \mathrm{MPa}$ stress range is shown in Figure 23. Collapse reaches a maximum in both types of samples for a vertical stress of about $2 \mathrm{MPa}$. At higher vertical stresses collapse decreases gradually. The distance between the two curves also reduces as the vertical stress increases.

The model is now used to explore in more detail its ability to reproduce the observed effects of compacting dry and wet of optimum (set of samples WD and DD, in Figs. 5 and 23). Data is 
available for constant suction oedometer loading starting on the common (dry density - water content) state (WD = DD), which corresponds to an initial suction $s=1 \mathrm{MPa}$.

Dry and wet of optimum compaction is distinguished exclusively by the initial microstructural state variable, $\xi_{m 0}$. All the remaining model parameters for the two samples analyzed take the same value (Table 1). The slopes of the virgin compression lines for saturated conditions $(\lambda(0))$ and the elastic coefficient $(\bar{\kappa})$ were approximated from test results. Values of $\bar{r}$ and $\bar{\beta}$, which define compressibility for unsaturated conditions, have been estimated to fit the collapse variation with stress level. The value for parameter $\bar{s}_{\lambda}$ corresponds to an average value of parameter $P_{0}$ of Van Genuchten water retention curves (see below). A low reference stress $\bar{p}_{c}$ was also selected.

The model proposed requires information on the water retention properties for the calculation of $\bar{S}_{r} s$. Water retention curves of Barcelona silty clay for several void ratios were reported by Barrera (2002). Figure 24 shows the experimental data. These curves, have been adopted to estimate the water retention behaviour of samples WD and DD by means of a Van Genuchten (1980) model. The dependence of the water retention behaviour with void ratio has been introduced in the model in the same simple way used for the synthetic cases presented in the previous section, i.e. assuming a linear variation of the parameter $P_{0}$ (which controls the air entry value) with void ratio. The model approximation to the reported retention curves is also plotted in Figure 24 . The Van Genuchten expression and the values of the parameters chosen for calculations are indicated in Table 1. The effect of the microstructure on the water retention curve has been neglected and a unique relationship between suction, degree of saturation and void ratio has been assumed for both samples.

Suriol et al. (1998) reported the compression curves of DD and WD samples for $\mathrm{s}=1 \mathrm{MPa}$ and for saturated conditions to a maximum vertical stress of $1.50 \mathrm{MPa}$ only (Figure 25). However, the reported collapse strains at different confining stresses in the range 0-8 $\mathrm{MPa}$ (Fig. 23) allow an 
estimation of the compression curves of DD and WD samples for the entire stress range. They are shown in Figure 26.

The constitutive model was first used to reproduce the saturated compression line in the range $0-1.5$ MPa (loading and unloading) (Fig. 25). The comparison between model calculations and experiments is quite satisfactory. The calculated saturated compression line was then extended to the entire loading range for the $\mathrm{DD}$ and WD compaction conditions (Fig. 26). The model reproduces satisfactorily the experimental results and correctly predicts the differences in compression behaviour associated with different microstructure. It is recalled that only a single variable, namely the initial microstructural state $\left(\xi_{m 0}\right)$ distinguishes the two compaction conditions, the rest of material parameters are identical in both samples. It is remarkable that the complexities of the microstructure can be adequately represented by a single state variable.

A further comparison of model performance and experimental data is given in Figure 27, which shows the collapse strains of both series of tests (DD and WD) plotted in terms of net applied stress. The model correctly predicts the maximum of collapse, its progressive decay towards a zero value at high applied stresses and the higher intrinsic collapsibility of the sample compacted dry of optimum. All these effects are directly linked with the initial microstructure of the soil and its evolution during the application of a stress-suction path.

The initial LC yield loci of DD and WD samples is plotted in Figure 28a in term of constitutive stress and effective suction and in Figure $28 \mathrm{~b}$ in term of net stress and suction. In the first case a unique LC yield curve describe dry and wet of optimum conditions. When transformed to net stresssuction coordinates, two different initial LC curves describe dry and wet conditions. The shape of LC yield curves in Fig. 28b were already advanced by Alonso et al. (1987) and Gens (1995) when interpreting compression and wetting tests of samples compacted wet and dry of optimum. The available model at the time $(\mathrm{BBM})$ required a different set of parameters (namely $r$ and $\beta$ ) to describe compaction induced microstructure. The model described here confirms the assumption 
made in the mentioned papers and provides a more compact and comprehensive description of compacted soil behaviour.

\section{CONCLUDING REMARKS}

Understanding the behaviour of compacted soils requires not only information on the as-compacted density and water content (or equivalent information in terms of yield stress and suction, as suggested here) but also a proper consideration of microstructure. The review of compacted soil behaviour presented in the first part of the paper has highlighted the relevance of microstructure. A conceptual framework that incorporates microstructural information and it accounts for the behaviour of compacted soils throughout the compaction plane has been put forward.

Microstructure is quantified by a state variable, $\xi_{m}$, the ratio of microvoid ratio and total void ratio. The microvoid ratio tends to maintain its original "as compacted" value during subsequent stress suction-paths in low to medium plasticity clayey soils. Changes in total void ratio associated with loading and suction changes, however, modify the microstructural state variable that becomes a state parameter with direct influence on effective stress and effective suction.

The interpretation of pore size distribution data of a number testing programs on compacted soils, covering a reasonably complete range of dry densities and water contents, has led to the establishment of the pattern of $\xi_{m 0}$ throughout the compaction plane. This state variable opens the way for a systematic evaluation of microstructural effects on measurable "macroscopic" engineering variables, such as elastic stiffness, strength, compressibility, yielding behaviour or permeability. All of them are influenced to a larger (permeability) or smaller (drained strength) extent by microstructure.

The framework is the bases of a constitutive model defined in terms of an effective suction and a constitutive stress that include microstructural information. The proposed constitutive stress was shown previously to be useful in predicting elastic stiffness and strength of unsaturated soils. The 
present work has concentrated on the analysis of compressibility and the associated concepts of collapse and yielding of unsaturated compacted soils. It has been shown that relevant engineering properties of a compacted soil can be explained by a set of common material (constitutive) parameters, the initial stress conditions defined by an initial yield stress, $p_{o}^{*}$, and a suction, $s$, and an additional state variable, $\xi_{m}$, that describes the microstructure which varies across the compaction plane,

Including $\xi_{m}$ in the definition of constitutive stress and effective suction has some significant advantages:

- $\quad$ It is a very simple option because only one variable is required to quantify microstructure.

- It captures the intrinsic volumetric behaviour of compacted soils and, in particular, the observed differences when compacting dry or wet of optimum.

- It provides a realistic interpretation of experimental compression lines for a wide range of applied stresses for both, constant suction or undrained loading conditions. The collapse maximum often observed is explained in a natural way.

- $\quad$ Existing constitutive models can be enhanced by including $\xi_{m}$ with a limited effort.

The model proposed requires information on the water retention properties. A desirable feature of the analysis in this case would be to include a microstructural information, such as $\xi_{m}$, into the formulation of the water retention behaviour, a proposal already put forward by Romero et al. (2011). In this way, the entire coupled hydromechanical model will require only a reduced number of material parameters. It has been shown that the model is consistent with a number of experimental observations.

Naturally the characterization of complex microstructure by a single variable and the assumption that the microstructural void ratio remains unchanged are simplifications that should be reviewed when some other aspects of compacted soil behaviour involving deviatoric loading or anisotropy 
effects are considered. In particular, extension of this model to expansive clays will require a relaxation of the assumption of a constant microstructural void ratio. However, the success of this approach in representing the behaviour of compacted soils suggests that it can be a very useful platform for subsequent developments and generalizations.

\section{REFERENCES}

Alonso, E.E. \& Pinyol, N.M. (2008) Unsaturated soil mechanics in earth and rockfill dam engineering. Keynote Lecture. Proc. $1^{\text {st }}$ Eur. Conf. on Unsaturated Soils (Durham, UK) 1: 3-32.

Alonso, E.E., Gens, A. \& Hight, D. (1987) Special problem soils. General Report. Proc. $9^{\text {th }}$ Eur. Conf. on Soil Mech. and Found. Engng, (Dublin, Ireland) 3: 1087-1146.

Alonso, E.E., Gens, A. \& Josa, A. (1990). A constitutive model for partially saturated soils. Géotechnique 40(3): 405-430.

Alonso, E.E., Josa, A. \& Gens, A. (1992) Modelling the behaviour of compacted soils upon wetting. Raul Marshall Volume. Soc. Mexicana de Mecánica de Suelos (México): 207-223.

Alonso, E.E., Pereira, J.M. Vaunat, J. \& Olivella, S. (2010) A microstructurally based effective stress for unsaturated soils. Géotechnique 60(12): 913-925.

Barrera, M. (2002) Estudio experimental del comportamiento hidromecánico de suelos colapsados. PhD Thesis. Universitat Politècnica de Catalunya, Barcelona, Spain.

Benatti J.C.B., Miguel, M.G., Rodrigues, R.A. \& Vilar, O.M. (2011) Collapsiblity study for tropical soil profile using oedometric test with controlled suction. Unsaturated soils. E. Alonso \& A. Gens (eds). Balkema, Vol. 1, 193-198

Benson, C.H., Zhai, H. \& Wang, X. (1992) Estimating hydraulic conductivity of compacted clay liners. J. Geotech. Engng., 120(2) ASCE: 366-387.

Bishop, A.W. (1959) The principle of effective stress. Tecknisk Ukeblad, 106(39): 859-863. 
Buenfil C.M., Romero, E., Lloret, A. \& Gens, A. (2004) Experimental study on the hydromechanical behaviour of a silty clay. Proceedings of the Second International Workshop on Unsaturated Soils, Anacapri, Italy. A. Tarantino and C. Mancuso, eds. Taylor \& Francis, 15-29.

Cox, D.W. (1978) Volume change of compacted clay fill. Clay Fills. ICE (London): 79-86.

Delage, P. \& Lefebvre, G. (1984) Study of the structure of a sensitive Champlain clay and of its evolution during consolidation. Canadian Geotechnical Jnl. 21(1): 21-35.

Delage, P., Audiger, M., Cui, Y.J. \& Howat, M. (1996) Microstructure of a compacted silt. Canadian Geotechnical Jnl. 33(1), 150-158.

Fredlund, D. \& Rahardjo, H. (1993) Soil mechanics for unsaturated soils. Wiley (London): 517 pp.

Gens, A. \& Alonso, E.E. (1992) A framework for the behaviour of unsaturated expansive soils. Canadian Geotechnical Jnl. 29(6): 761-773.

Gens, A. (1995) Constitutive modelling. Application to compacted soils. Proc. $1^{\text {st }}$ Int. Conf. on Unsaturated Soils (Paris, France) 3: 1179-1200.

Gens, A. (2010) Soil-environment interaction in geotechnical engineering. Géotechnique 15(1), 374.

Gens, A., Alonso, E.E., Suriol, J. \& Lloret, A. (1995) Effect of structure on the volumetric

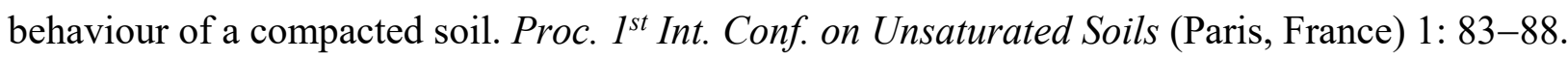

Gesto, J.M, Gens, A. \& Vaunat, J. (2011) Smoothing of yield surfaces and a reformulation of multisurface plasticity. XI International Conference on Computational Plasticity. Fundamentals and Applications (COMPLAS XI). E. Oñate, D.R.J. Owen, D. Peric and B. Suárez (Eds), 295-306.

Jommi, C. (2000) Remarks on constitutive modelling of unsaturated soils. In "Experimental evidence and theoretical approaches in unsaturated soils (Tarantino, A. \& Mancuso, C.). Rotterdam, Balkema. 139-153. 
Jotisankasa, A., Ridley, A. \& Coop, M. (2007) Collapse behavior of compacted silty clay in suction-monitored oedometer apparatus. Journal of Geotechnical and Geoenvironmental Engineering 133(7), 867-877.

Jotisankasa, A., Coop, M. \& Ridley, A. (2009) The mechanical behaviour of an unsaturated compacted silty clay. Géotechnique 59(5), 415- 428

Lambe, T.W. \& Whitman, R.V. (1969) Soil Mechanics, Wiley (New York): 553 pp.

Lambe, T.W. (1958) The engineering behaviour of compacted clay. J. Soil Mech. Found. Div., 84(SM2) ASCE: 1-35.

Lawton, E.C., Fragaszy, R.J. \& Hardcastle, J.H. (1989) Collapse of compacted clayey sand. J. Geotech. Engng., 115(9) ASCE: 1252-1267.

Lawton, E.C., Fragaszy, R.J. \& Hardcastle, J.H. (1991) Stress ratio effects on collapse of compacted clayey sand. J. Geotech. Engng., 117(5) ASCE: 714-730.

Lee, X. and Zhang, L.M. (2009) Characteristics of dual structure pore size distribution of soil. Canadian Geotechnical Jnl. 46, 129-141.

Leonards, G.A. (1955) Strength characteristics of compacted clays. ASCE Trans., 120: 1420-1454.

Li, Z.M. (1995) Compressibility and collapsability of compacted unsaturated loessial soils. Proc. $1^{\text {st }}$ Int. conf. on Unsaturated Soils (Paris, France) 1: 139-144.

Merchán, V. (2011) Small strain stiffness and residual strength of unsaturated Boom clay: A microstructural insight. PhD Thesis. Universitat Politècnica de Catalunya. Barcelona, Spain.

McGown, A. \& Collins, K. (1975) The microfabric of some expansive and collapsing soils. Proc. $5^{\text {th }}$ PanAm Conf. SMFE (Buenos Aires, Argentina) 1: 323-332.

Mitchell, J.K., Hooper, D.R. \& Campanella, R.G. (1965) Permeability of compacted clay. J. Soil Mech. \& Found. Engng. Div. ASCE, 91(4): 41-65. 
Monroy, R., Zdravkovic, L. \& Ridley, A. (2010) Evolution of microstructure in compacted London clay during wetting and loading. Géotechnique 60(2): 105-119.

Proctor, R.R. (1933) Fundamental principles of soil compaction. Engineering News Record, V11 n.9, 148-156.

Résendiz, D. (1980) Compaction conditions, state variables and engineering properties of compacted clay. Proc. Int. Conf. on Compaction (Paris, France) 1: 195-202.

Romero, E. \& Vaunat, J. (2000). Retention curves in deformable clays. In Experimental evidence and theoretical approaches in unsaturated soils (A. Tarantino and C. Mancuso), 91-106. Rotterdam: A. A. Balkema.

Romero, E. (2002) Characterization and thermo-hydro-mechanical behaviour of unsaturated Boom clay: An experimental study. PhD Thesis. Universitat Politècnica de Catalunya, Barcelona, Spain.

Romero, E. \& Simms, P. (2008) Microstructure investigations in unsaturated soils. A review with special attention to Mercury Intrusion Porosimetry and Environmental Scanning Electron Microscopy. Geotechnical and Geological Engineering, 26 (6), 705-72.

Romero, E., Della Vecchia, G. \& Jommi, C. (2011) An insight into the water retention properties of compacted clayey soils. Géotechnique 61(4): 313-328.

Romero, E., Gens, A. \& Lloret, A. (1999) Water permeability, water retention and microstructure of unsaturated compacted Boom clay. Engineering Geology 54: 117-127.

Santucci de Magistris, F. \& Tatsuoka, F. (2004) Effects of moulding water content on the stressstrain behaviour of a compacted silty sand. Soils \& Found. 44(2): 85-101.

Seed, H.B. \& Chan, C.K. (1959) Structure and strength characteristics of compacted clays. J. Soil Mech. Found. Div. 85 (SM5) ASCE: 87-128. 
Sheng (2011). Contitutive modelling of unsaturated soils: Discussion of fundamental principles. Unsaturated Soils (Alonso \& Gens). Balkema. Vol. 1. 91-112.

Shridharan, A., Altschaeffl, A.G. \& Diamond, S. (1971) Pore size distribution studies. J. Soil Mech. Found. Div. 97 (SM5), ASCE: 771-787.

Simms, P.H. \& Yanful, E.K. (2002) Predicting soil-water characteristic curves of compacted plastic soils from measured pore-size distributions. Géotechnique 52(4): 269-278

Suriol, J., Gens, A. \& Alonso, E.E. (1998) Behaviour of compacted soils in suction controlled oedometer. Proc. $2^{\text {nd }}$ Int. Conf. on Unsaturated Soils (Beijing, China) 1: 463-443.

Suriol, J. \& Lloret, A. (2007) Cambios en la estructura de suelos compactados frente a humedecimiento y secado. Ingeniería Civil, Madrid, 147, pp. 67-76.

Tarantino, A. \& de Col, E. (2008) Compaction behaviour of clay. Géotechnique 58(3): 199-214.

Tarantino, A. \& Tombolato, S. (2005) Coupling of hydraulic and mechanical behaviour in unsaturated compacted clay. Géotechnique 55(4): 307-317.

Thom, R., Sivakumar, R. Sivakumar, V. Murray, E.J. \& Mackinnon, P. (2007) Pore size distribution of unsaturated compacted kaolin: the initial states and final states following saturation. Géotechnique 57(5): 469-474.

Tinjum, J.M., Benson, C.H. \& Blotz, L.R. (1997) Soil-Water characteristic curves for compacted clays. J. Geotech. \& Geoenv. Engng. 123(11) ASCE: 1060-1069.

van Genuchten, M. T. (1980). Closed-form equation for predicting the hydraulic conductivity of unsaturated soils. Soil Sci. Soc. Am. J. 44(5), 892-898.

Vanapalli, S.K., Fredlund, D.G. \& Rufahl, D.E. (1999) The influence of soil structure and stress history on the soil-water characteristics of a compacted fill. Géotechnique 49(2): 143-159. 
Wheeler, S.J. \& Sivakumar, V. (1995) An elasto-plastic critical state framework for unsaturated soils. Géotechnique 45(1): 35-53.

Wheeler, S.J. \& Sivakumar, V. (2000) Influence of compaction procedure on the mechanical behaviour of an unsaturated compacted clay. Part 2: Shearing and constitutive modelling. Géotechnique 50(4): 369-376.

Zhou, A-N, Sheng, D, Scott W. Sloan, S.W. \& Gens, A. (2012a) Interpretation of unsaturated soil behaviour in the stress saturation space II: Constitutive relationships and validations. Computers and Geotechnics 43, 111-123

Zhou, A-N, Sheng, D, Scott W. Sloan, S.W. \& Gens, A. (2012b) Interpretation of unsaturated soil behaviour in the stress-saturation space, I: Volume change and water retention behaviour. Computers and Geotechnics 43, 178-187. 


\section{TABLES}

Table 1. Parameters and initial conditions for isotropic synthetic tests and oedometer tests on Barcelona silty clay samples.

\begin{tabular}{|c|c|c|c|c|c|c|}
\hline \multirow[b]{2}{*}{ Parameter } & \multirow[b]{2}{*}{ Definition } & \multirow[b]{2}{*}{ Units } & \multicolumn{2}{|c|}{ Synthetic case } & \multicolumn{2}{|c|}{ Barcelona silty clay } \\
\hline & & & $\begin{array}{l}\text { Sample } \\
\text { Dry }\end{array}$ & $\begin{array}{l}\text { Sample } \\
\text { Wet }\end{array}$ & $\begin{array}{l}\text { Sample } \\
\text { DD }\end{array}$ & $\begin{array}{l}\text { Sample } \\
\text { WD }\end{array}$ \\
\hline \multicolumn{7}{|c|}{ Mechanical parameters } \\
\hline $\bar{\kappa}$ & Elastic compressibility & - & \multicolumn{2}{|c|}{0.006} & \multicolumn{2}{|c|}{0.006} \\
\hline $\bar{\lambda}(0)$ & $\begin{array}{l}\text { Plastic compressibility } \\
\text { at zero effective suction }\end{array}$ & - & \multicolumn{2}{|c|}{0.07} & \multicolumn{2}{|c|}{0.07} \\
\hline$v$ & Poisson' ratio & - & \multicolumn{2}{|c|}{0.3} & \multicolumn{2}{|c|}{0.3} \\
\hline$M$ & $\begin{array}{l}\text { Slope of critical state } \\
\text { strength line }\end{array}$ & - & \multicolumn{2}{|c|}{-} & \multicolumn{2}{|c|}{1.2} \\
\hline $\bar{p}_{c}$ & Reference stress & $\mathrm{MPa}$ & \multicolumn{2}{|c|}{0.001} & \multicolumn{2}{|c|}{0.001} \\
\hline $\bar{s}_{\lambda}$ & $\begin{array}{l}\text { Minimum value of } \\
\text { effective suction } \\
\text { affecting plastic } \\
\text { volumetric } \\
\text { compressibility. It is } \\
\text { equivalent to an air } \\
\text { entry value }\left(P_{0}\right)\end{array}$ & $\mathrm{MPa}$ & \multicolumn{2}{|c|}{0.25} & \multicolumn{2}{|c|}{0.25} \\
\hline $\bar{r}$ & $\begin{array}{l}\text { Parameter that } \\
\text { establishes the } \\
\text { minimum value of the } \\
\text { compressibility } \\
\text { coefficient for high } \\
\text { values of effective } \\
\text { suction }\end{array}$ & - & \multicolumn{2}{|c|}{0.8} & \multicolumn{2}{|c|}{0.8} \\
\hline $\bar{\beta}$ & $\begin{array}{l}\text { Parameter that controls } \\
\text { the rate of increase in } \\
\text { stiffness with effective } \\
\text { suction }\end{array}$ & $\mathrm{MPa}^{-1}$ & \multicolumn{2}{|c|}{0.75} & \multicolumn{2}{|c|}{0.8} \\
\hline$\xi_{m 0}$ & Initial microstructural & - & 0.34 & 0.38 & 0.36 & 0.41 \\
\hline
\end{tabular}




\begin{tabular}{|c|c|c|c|c|}
\hline & state variable & & & \\
\hline$n_{\text {smoothing }}$ & $\begin{array}{l}\text { Parameter that defines } \\
\text { the degree of smoothing } \\
\text { in Eq. ( } 7 \text { ) }\end{array}$ & - & 3 & 3 \\
\hline \multicolumn{5}{|c|}{ Water retention curve. Van Genuchten model. } \\
\hline$S_{r \min }$ & \multirow{5}{*}{$\begin{array}{l}\frac{S_{r}-S_{r \min }}{S_{r \max }-S_{r \min }}=\left(1+\left(\frac{s}{P_{0}}\right)^{\frac{1}{1-\lambda}}\right)^{-\lambda} \\
P_{0}=a^{V G} e+b^{V G}\end{array}$} & - & 0 & 0 \\
\hline$S_{r \max }$ & & - & 1 & 1 \\
\hline $\mathrm{a}^{\mathrm{VG}}$ & & $\mathrm{MPa}$ & -0.25 & -0.25 \\
\hline$b^{V G}$ & & $\mathrm{MPa}$ & 0.4 & 0.4 \\
\hline$\lambda$ & & - & 0.35 & 0.35 \\
\hline \multicolumn{5}{|c|}{ Initial conditions } \\
\hline$e_{0}$ & Initial void ratio & - & 0.538 & 0.538 \\
\hline$p_{0}^{*}$ & $\begin{array}{l}\text { Yield stress at zero } \\
\text { effective suction }\end{array}$ & $\mathrm{MPa}$ & 0.45 & 0.45 \\
\hline$s_{0}$ & Initial suction & $\mathrm{MPa}$ & 1 & 1 \\
\hline
\end{tabular}




\section{FIGURES}

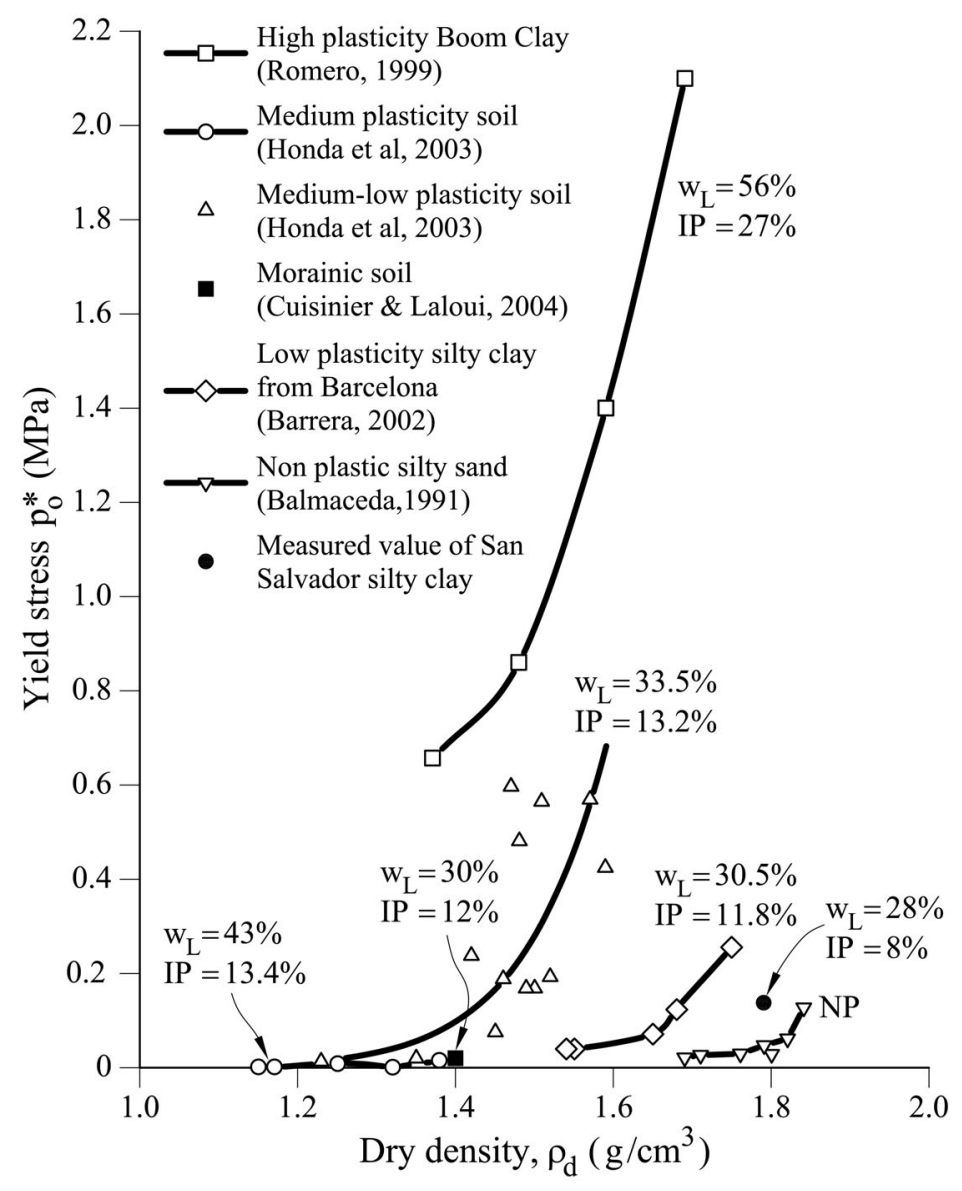

Figure 1: Relationship between the isotropic yield stress at saturated conditions and dry density of several soil types (Alonso \& Pinyol, 2008). 


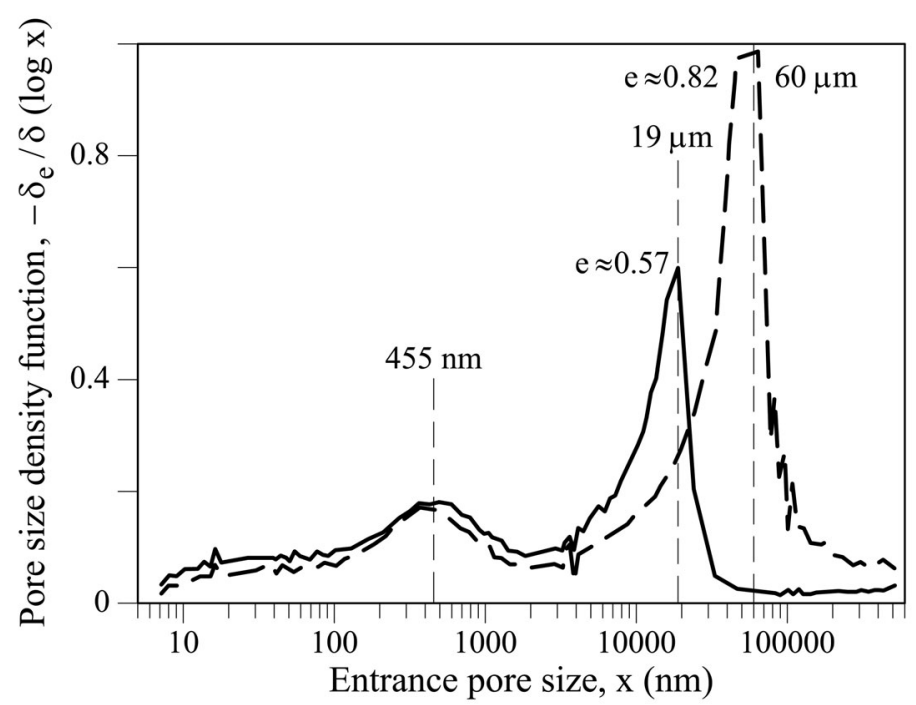

a)

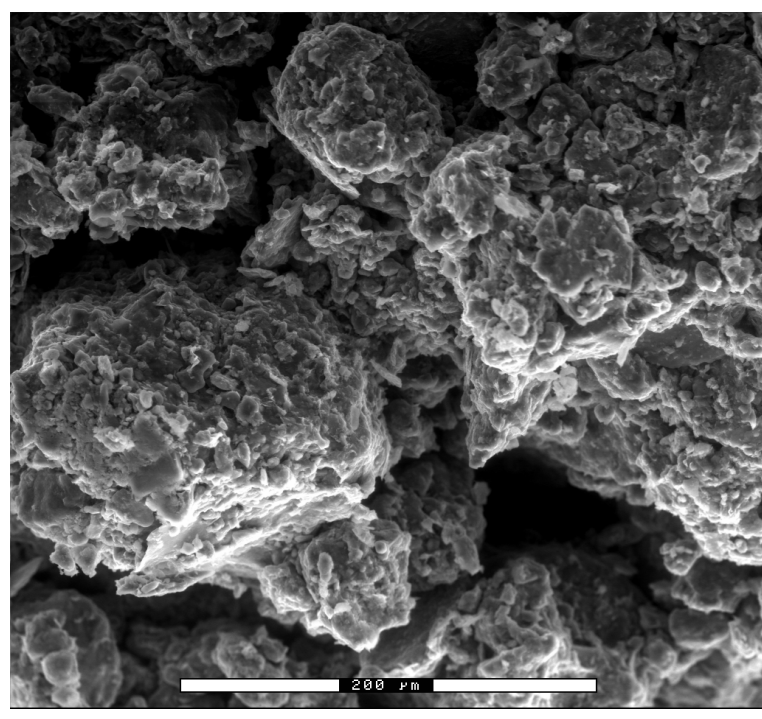

b1)

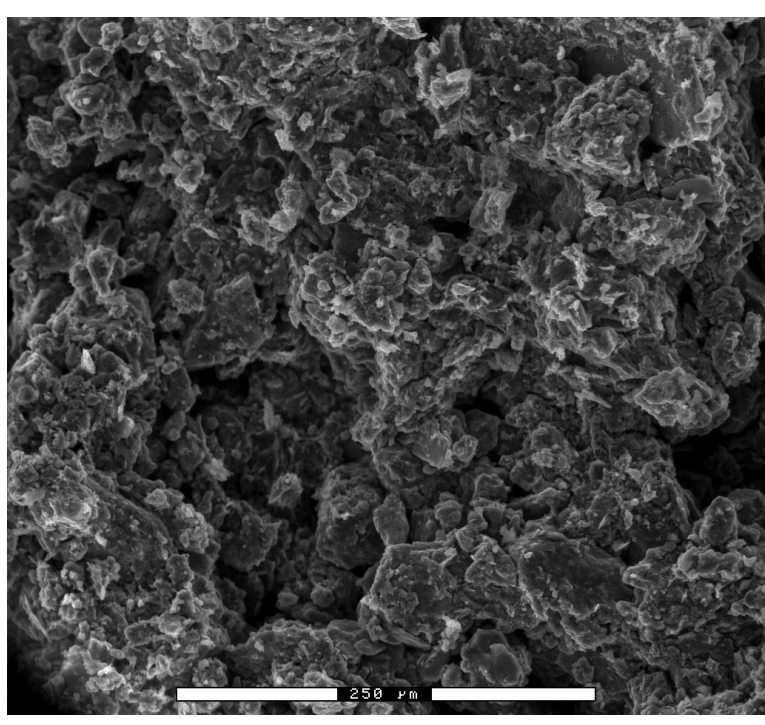

b2)

Figure 2: Evolution of microstructure during loading. a) Pore size distribution; b) ESEM observations. Statically compacted low plasticity Barcelona silty clay. b1: e $=0.82 ; \mathrm{b} 2$ : $\mathrm{e}=0.57$. After Buenfil et al (2004) 


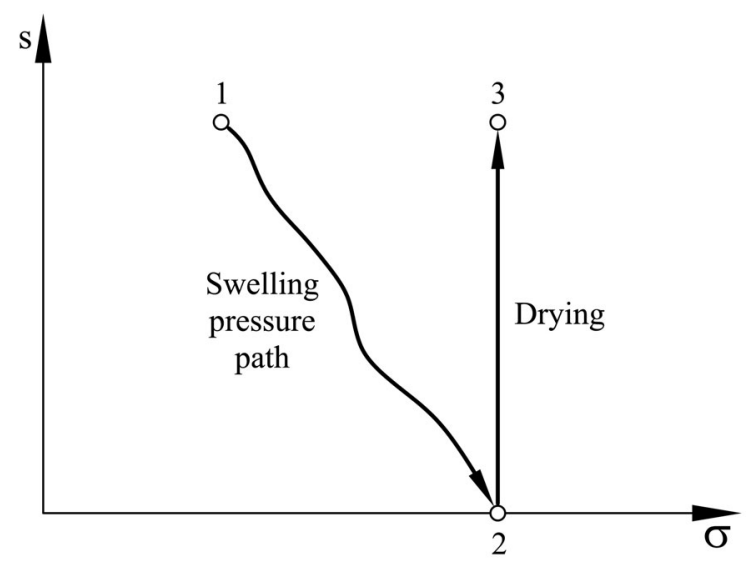

a)

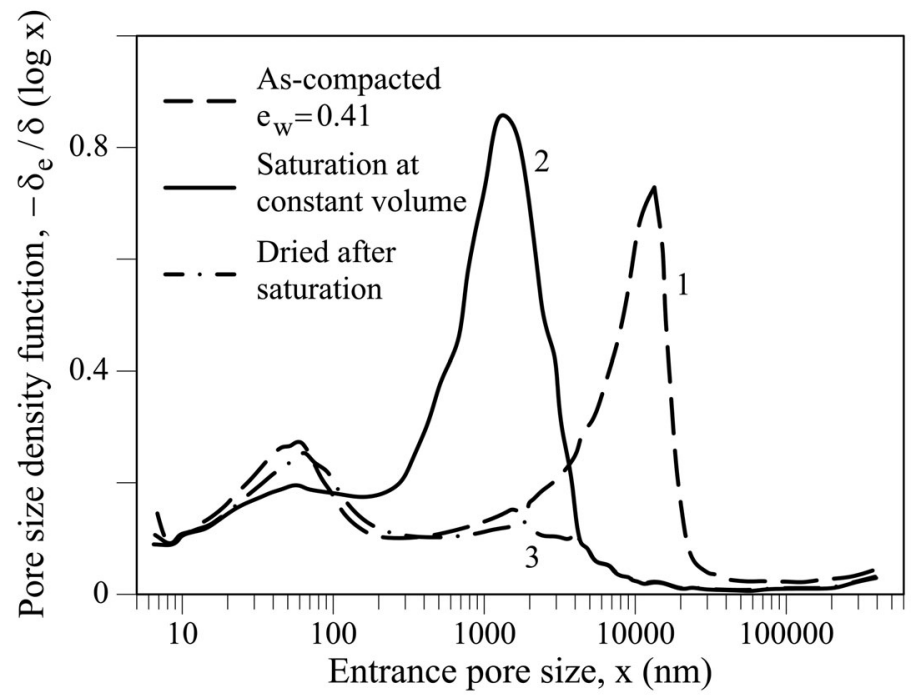

b)

Figure 3: Evolution of pore size distribution of compacted high plasticity Boom clay during loading and suction changes. a) Stress path; b) Pore size distribution at the three stress-suction points indicated in a). From Romero et al. (2011). 


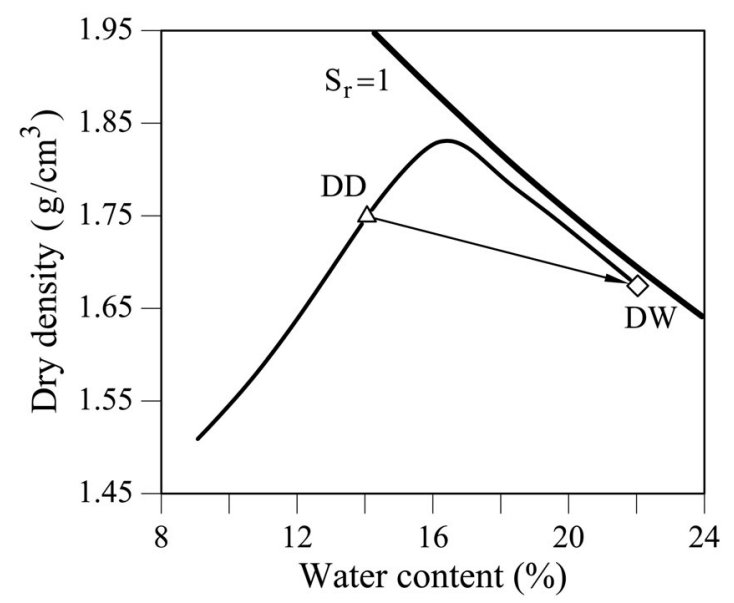

a)

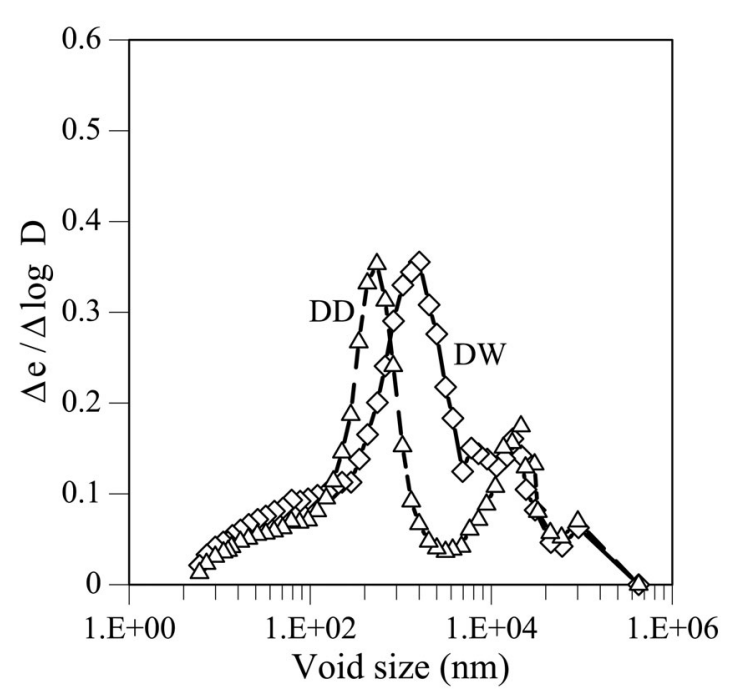

b)

Figure 4: Statically compacted Barcelona silty clay. a) Compaction state of samples DD and DW; b) Pore size distributions. After Suriol et al. (1998) and Suriol \& Lloret, (2007). 


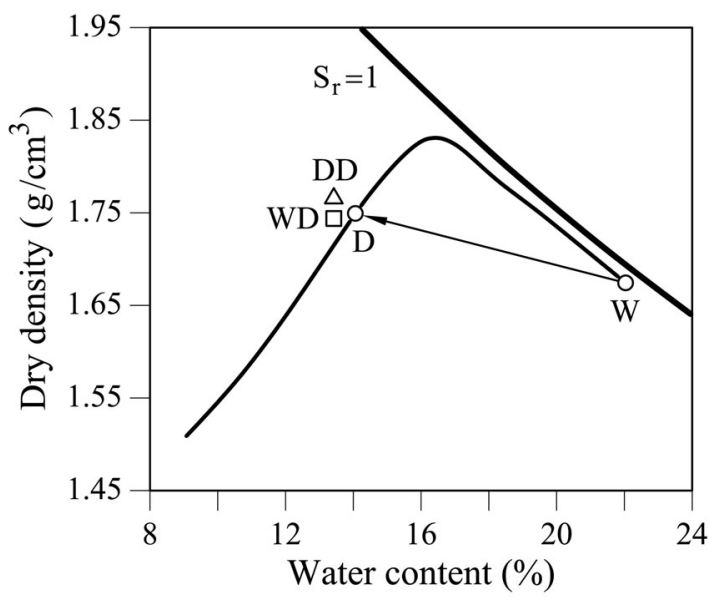

a)

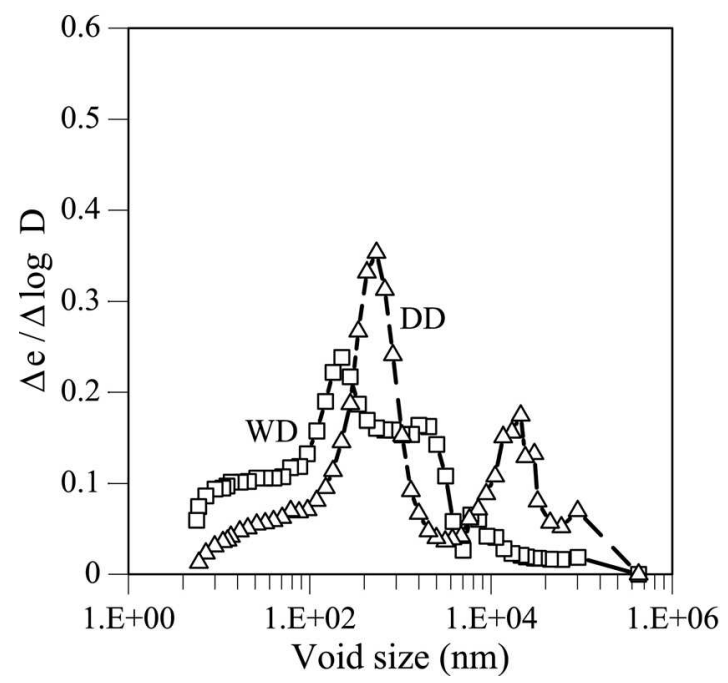

b)

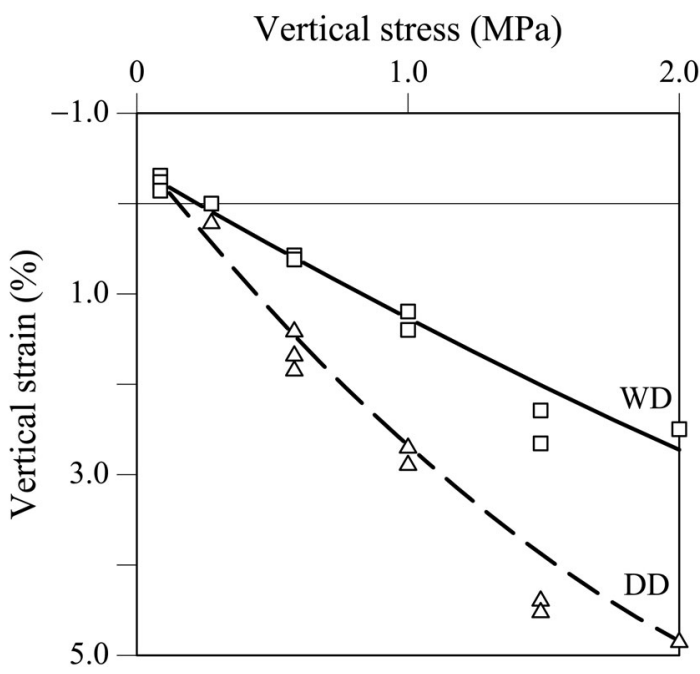

c)

Figure 5: Statically compacted Barcelona silty clay. a) Compaction state of samples DD and WD; b) Pore size distributions; c) Measured collapse strains in loading at constant suction and full wetting. After Suriol et al. (1998) and Suriol \& Lloret, (2007). 


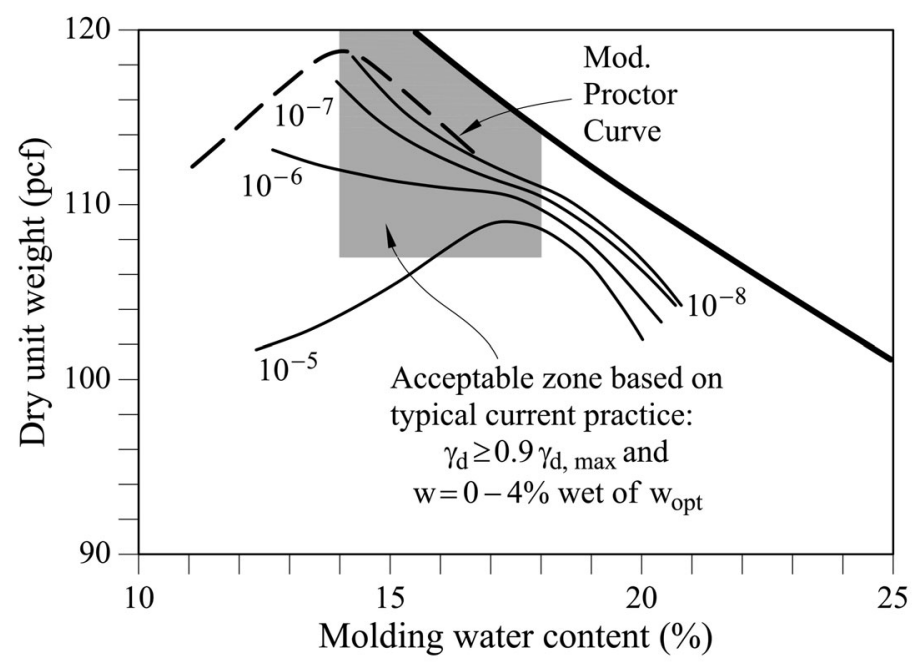

Figure 6: Contours of permeability, under saturated conditions, for samples of silty clay compacted by kneading action. Mitchell et al. (1965).

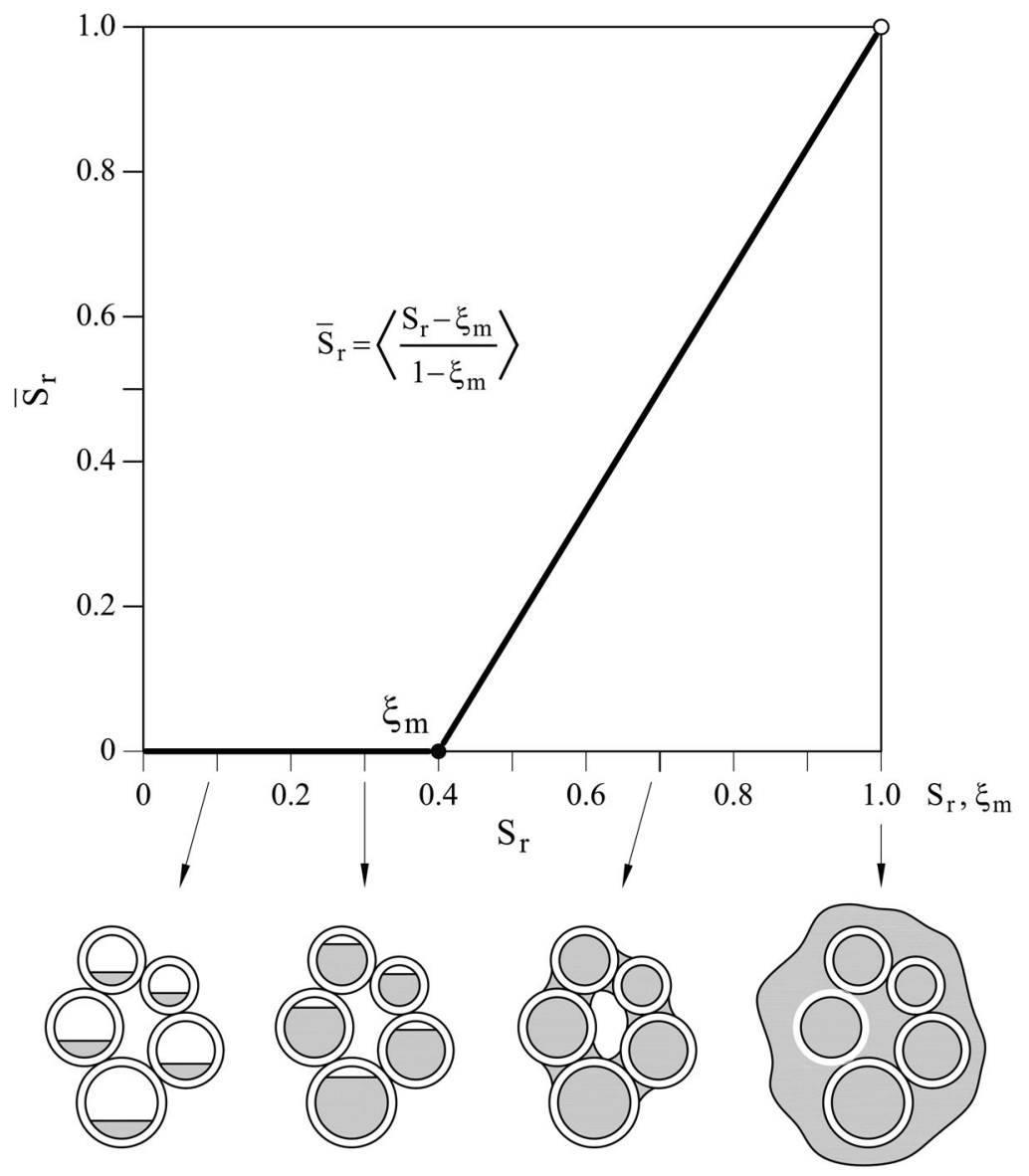

Figure 7: Definition of effective degree of saturation. 


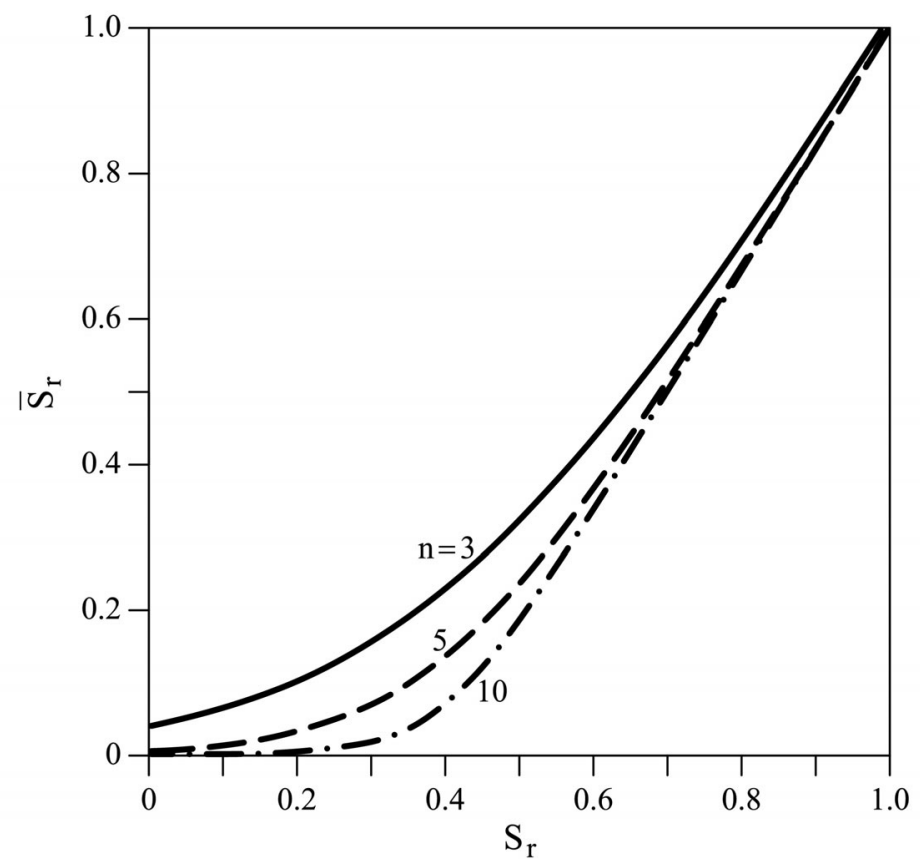

Figure 8: Effect of the parameter $\mathrm{n}$ on the effective degree of saturation for $\xi_{m}=0.3$.

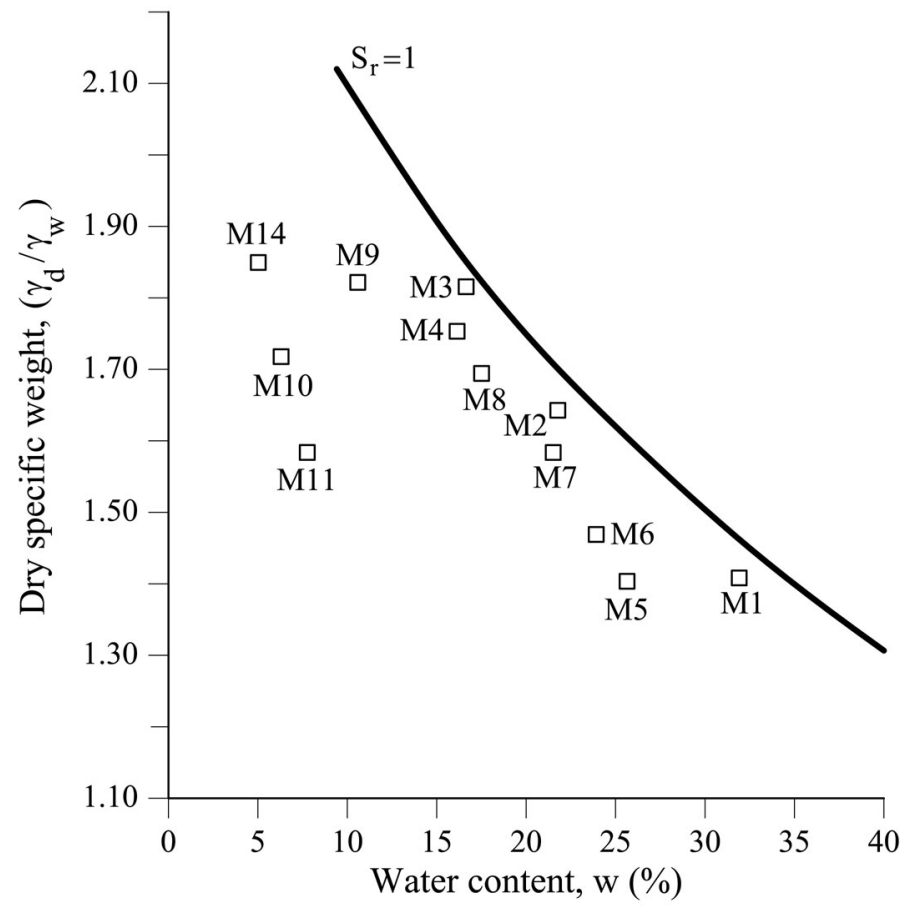

Figure 9: Compacted samples of Boom clay tested by Merchán (2011). 

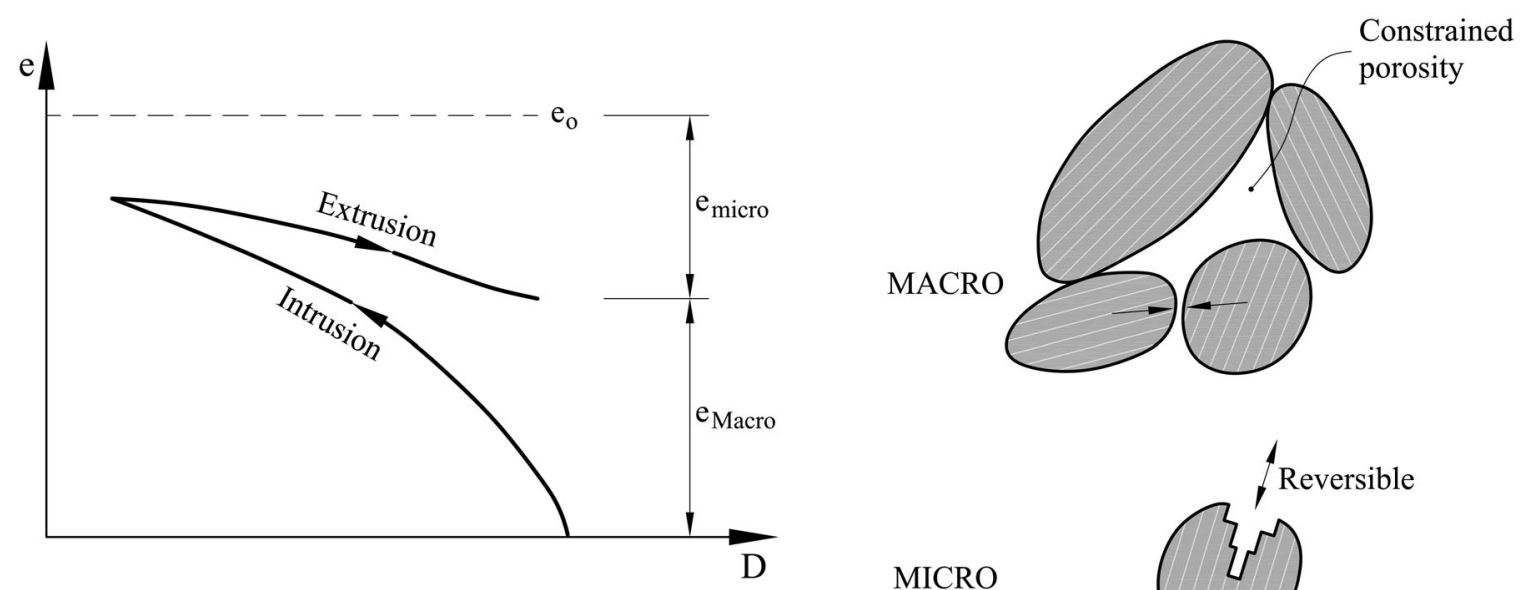

MICRO

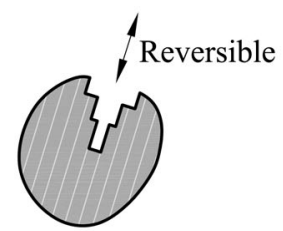

Figure 10: Scheme of intrusion-extrusion stages of an MIP test and interpretation in terms of micro and macro void ratios. After a proposal by Delage and Lefebvre (1984).

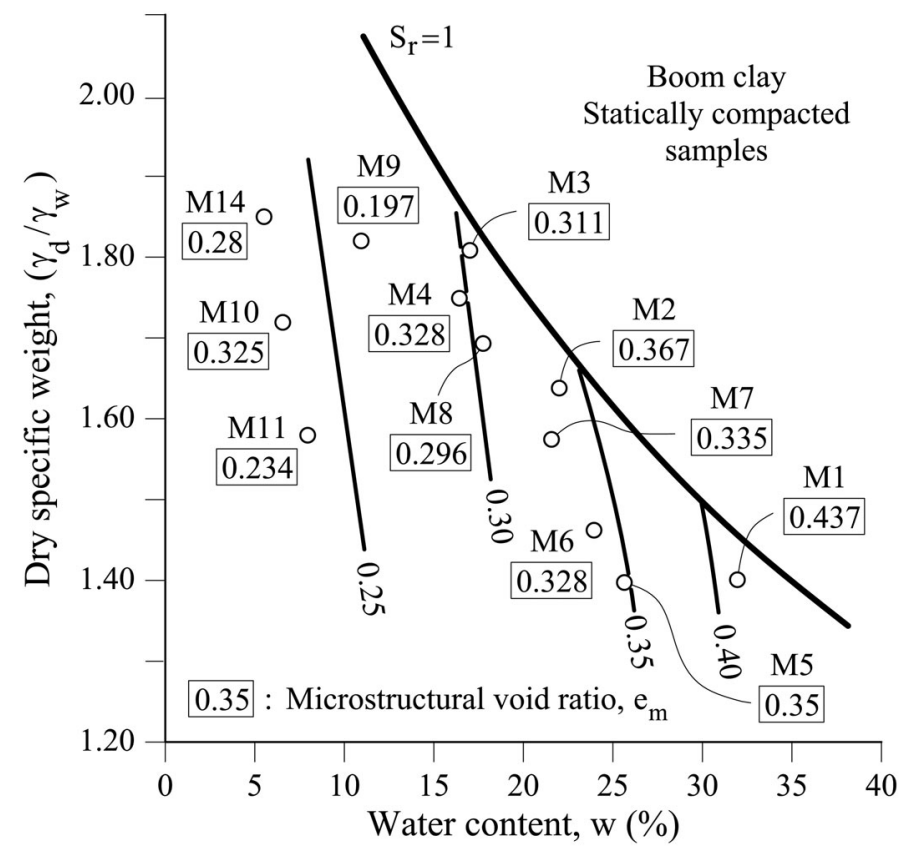

Figure 11: Contours of equal microstructural void ratio, $e_{m}$, for compacted Boom clay. Compaction data taken from Merchán (2011). 


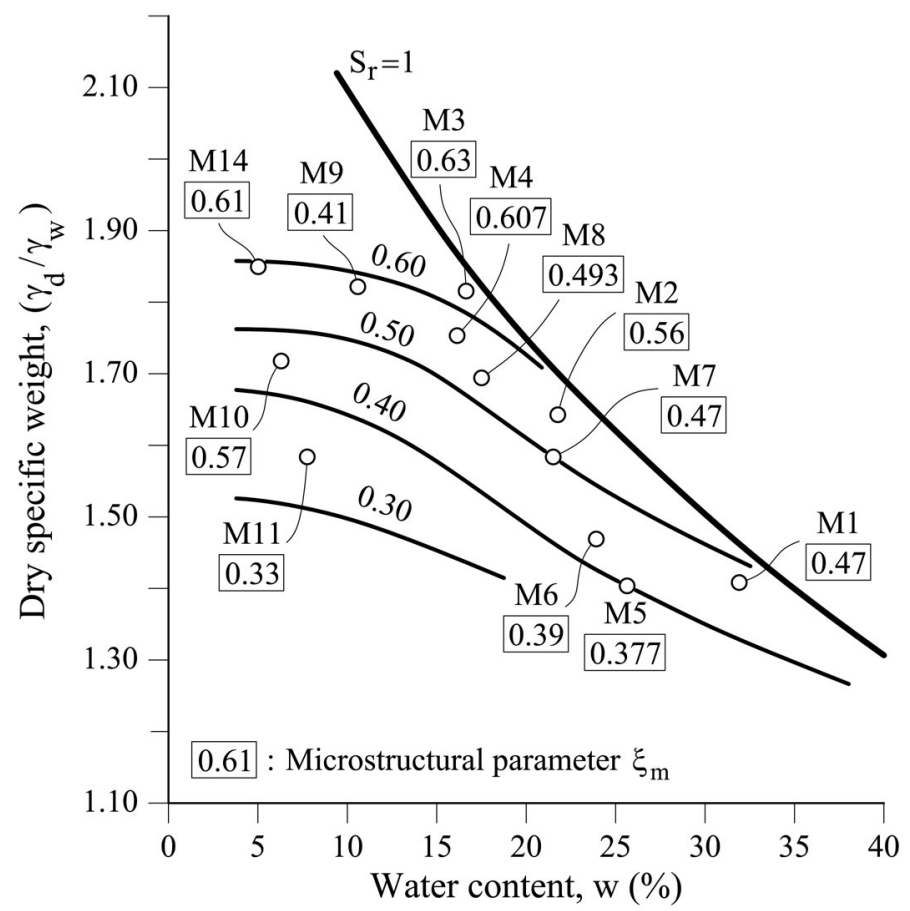

Figure 12: Contours of equal microstructural parameter, $\xi_{m}$, for compacted Boom clay. Compaction data taken from Merchán (2011).
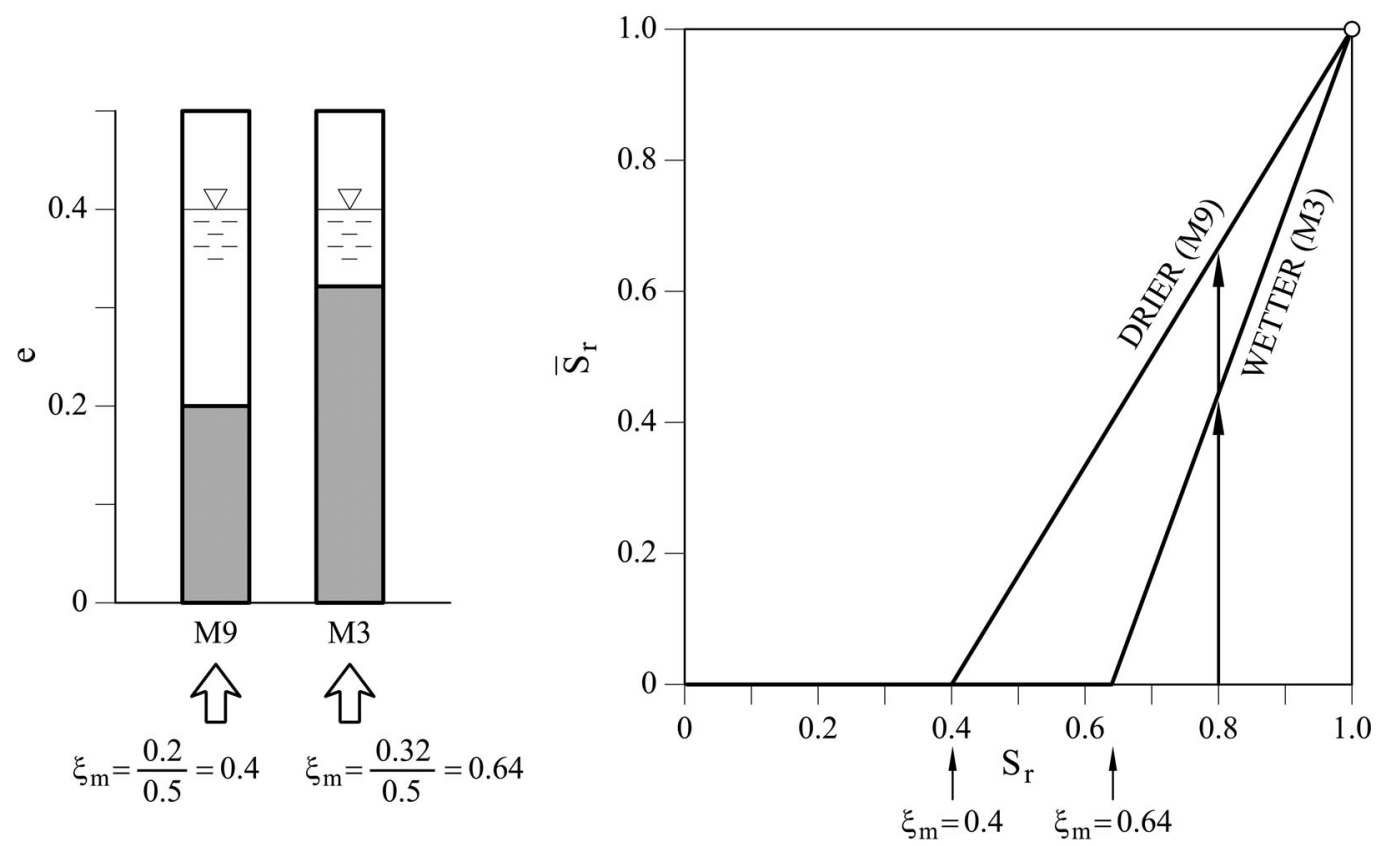

Figure 13: Micro and macro void ratios of specimens M9 and M3 after compaction and associated effective degree of saturation for a degree of saturation of 0.8 . 


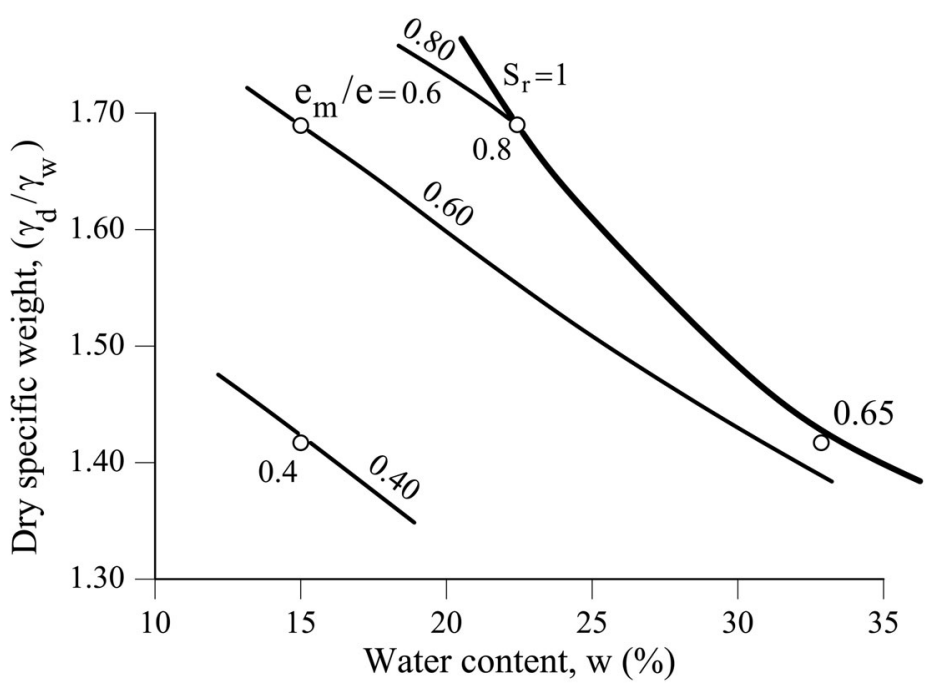

Figure 14: Contours of equal microstructural parameter, $\xi_{m}$, for compacted Boom clay. Compaction data taken from Romero et al. (2011).

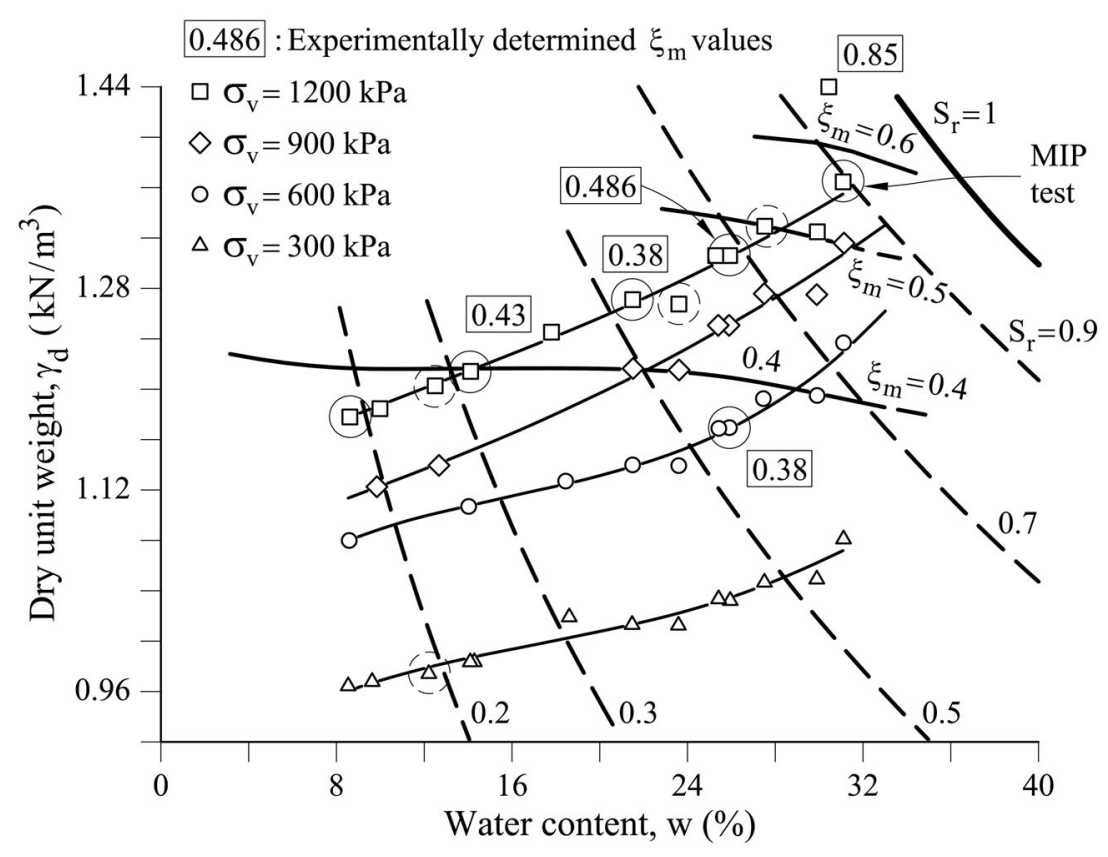

Figure 15: Contours of equal microstructural parameter, $\xi_{m}$, for compacted kaolin. Compaction data taken from Tarantino and de Col (2008). 


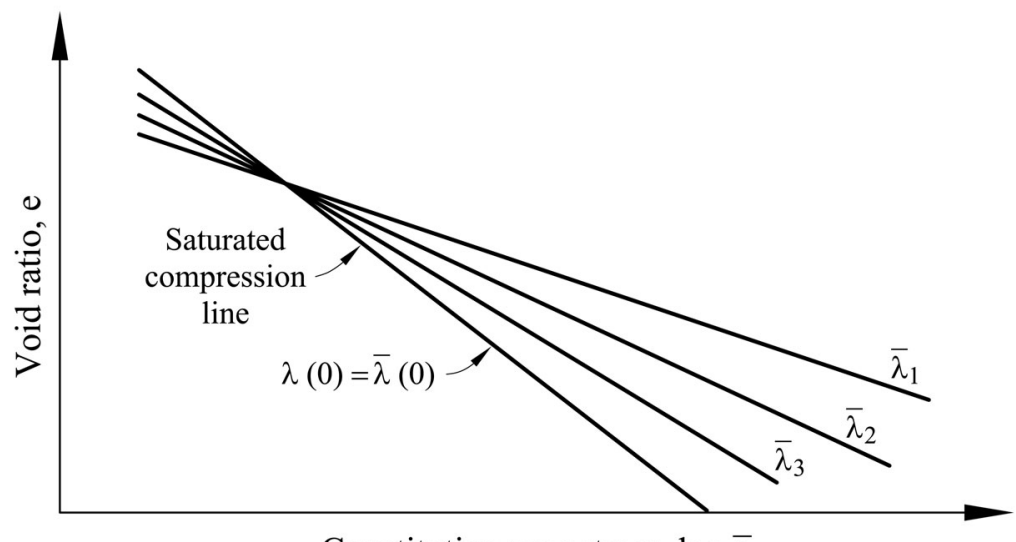

Constitutive near stress, $\log \overline{\mathrm{p}}$

Figure 16: Definition of compression lines in terms of effective stress $\log \bar{p}=\log \left(p_{n e t}+\bar{S}_{r} s\right)$.

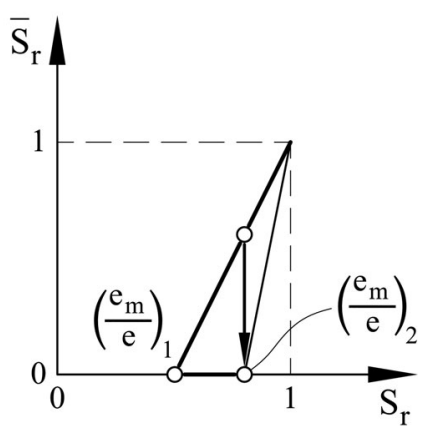

a)

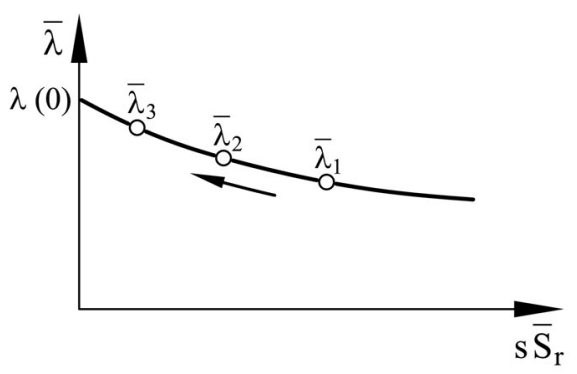

b)

Figure 17: a) Effect of increasing microstructural void ratio on effective degree of saturation for a constant degree of saturation; b) effect of decreasing effective suction on compressibility coefficient, $\bar{\lambda}$ 


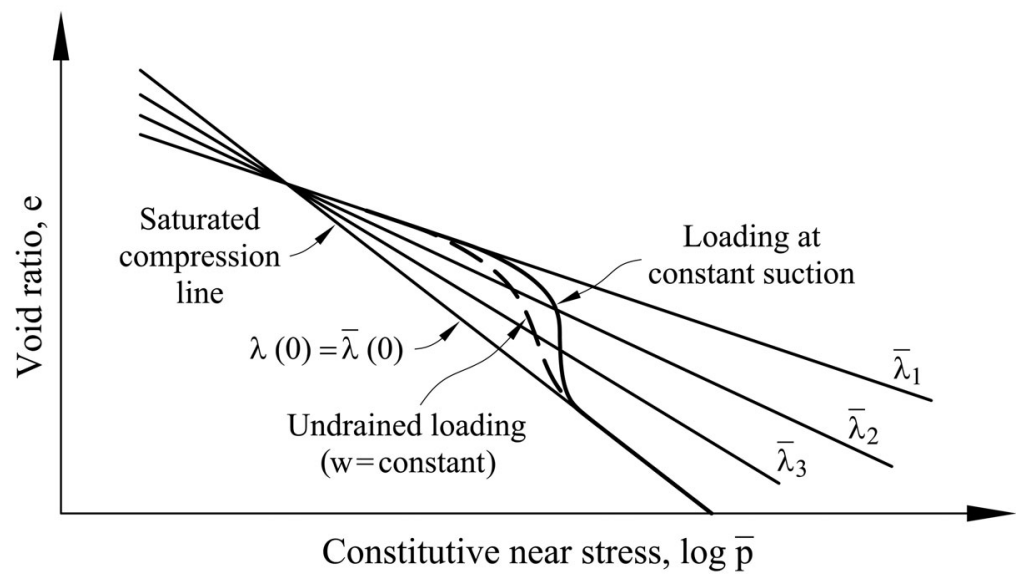

Figure 18: Estimated compression behaviour of unsaturated soil for drained (constant suction) and undrained (constant water content) isotropic loading in terms of the effective stress $\log \bar{p}=\log \left(p_{\text {net }}+\bar{S}_{r} s\right)$.

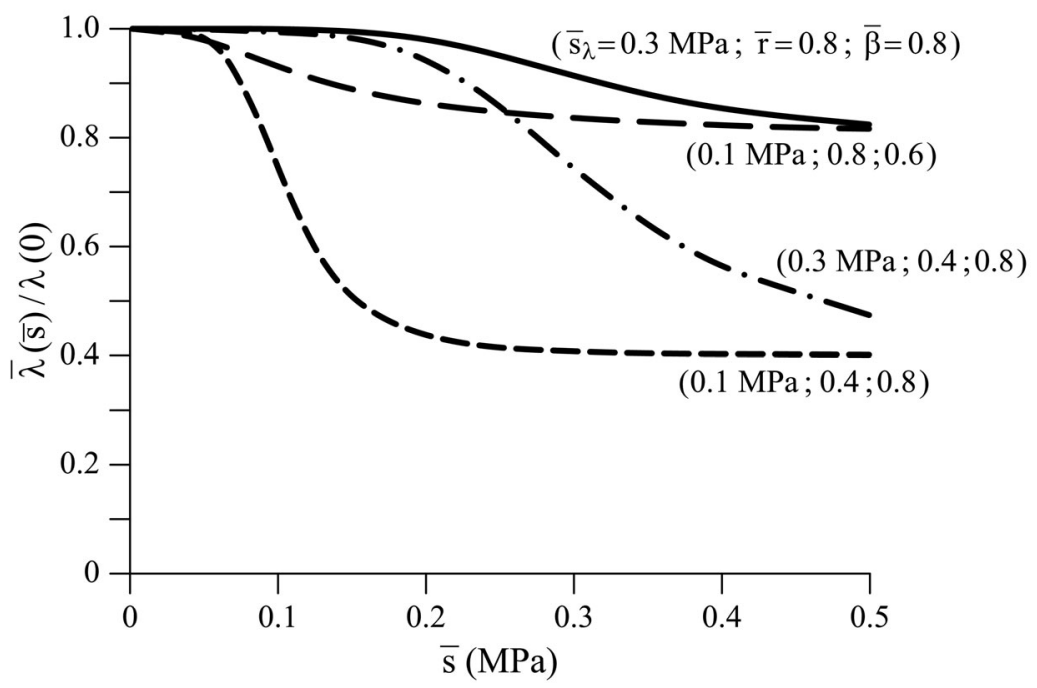

Figure 19: Variation of isotropic compressibility with effective suction for different parameter values 


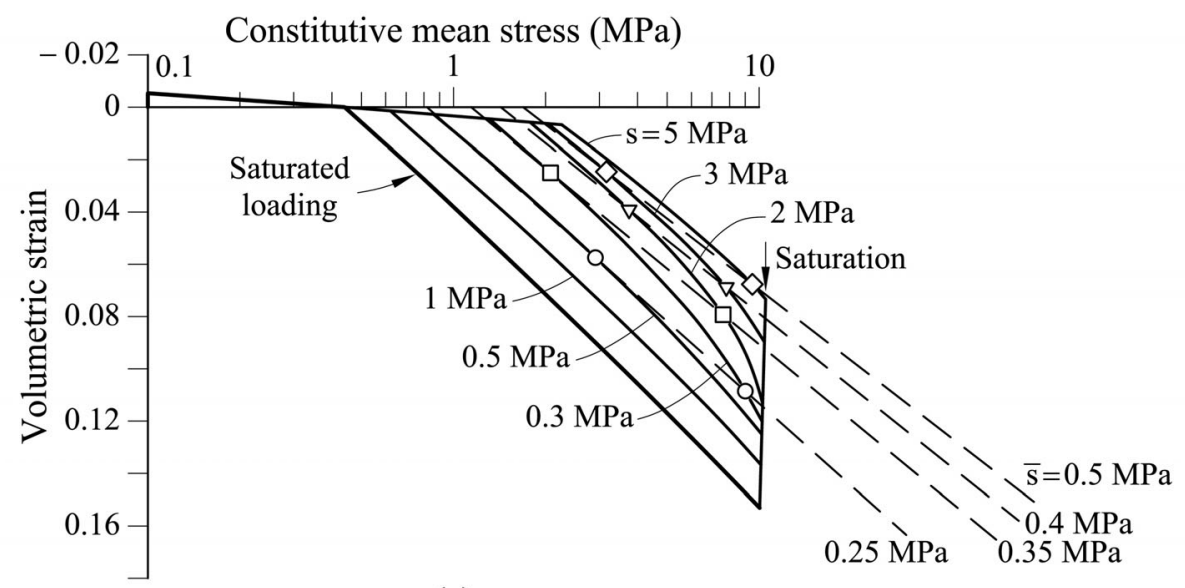

(a)

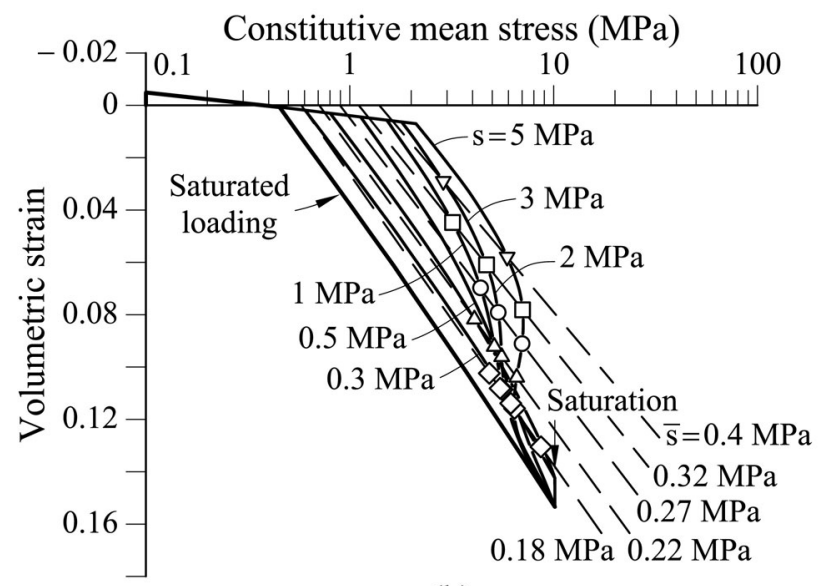

(b)

Figure 20. Synthetic isotropic tests in terms of constitutive stress and effective suction Compression response at different constant suctions. (a) Dry compaction: Sample SI-D (b) Wet compaction: Sample SI-W 


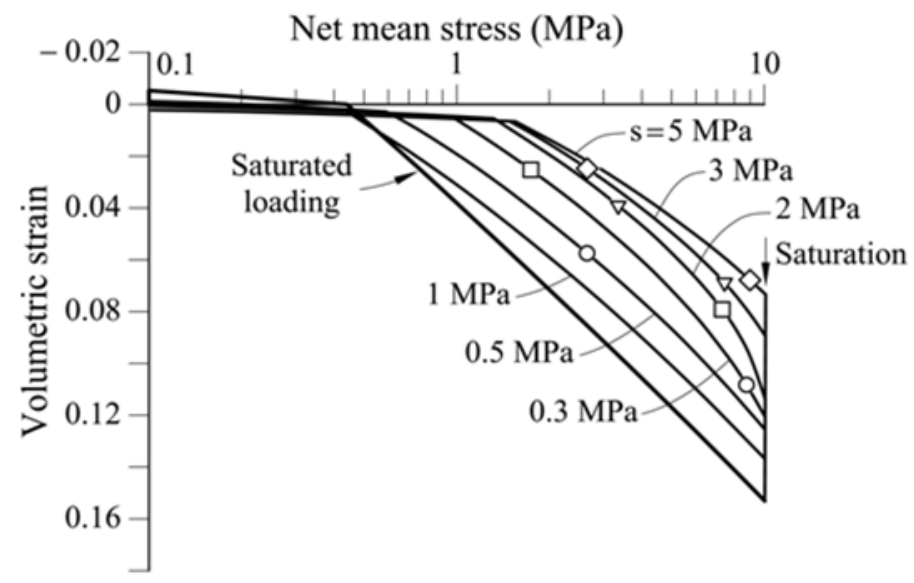

(a)

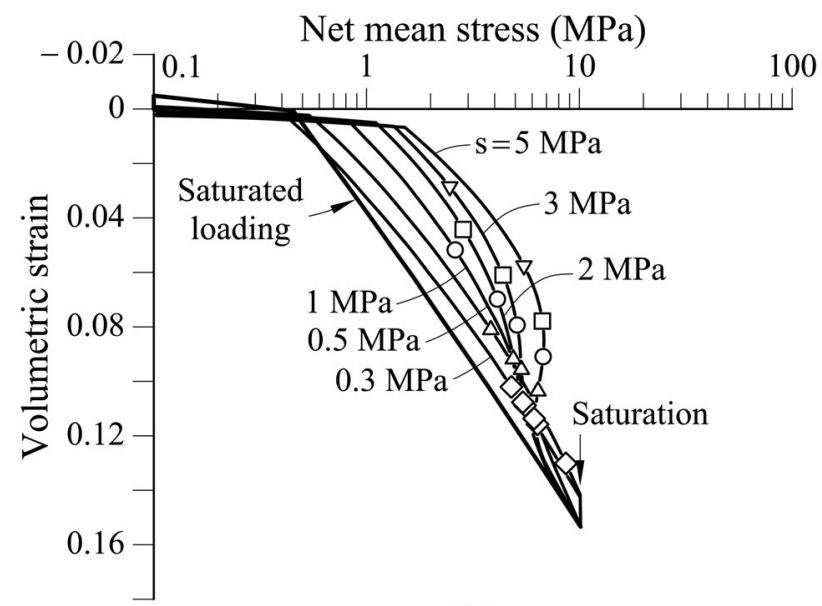

(b)

Figure 21. Synthetic isotropic tests in terms of net stress and suction. Compression response at different constant suctions. (a) Dry compaction: Sample SI-D (b) Wet compaction: Sample SI-W 


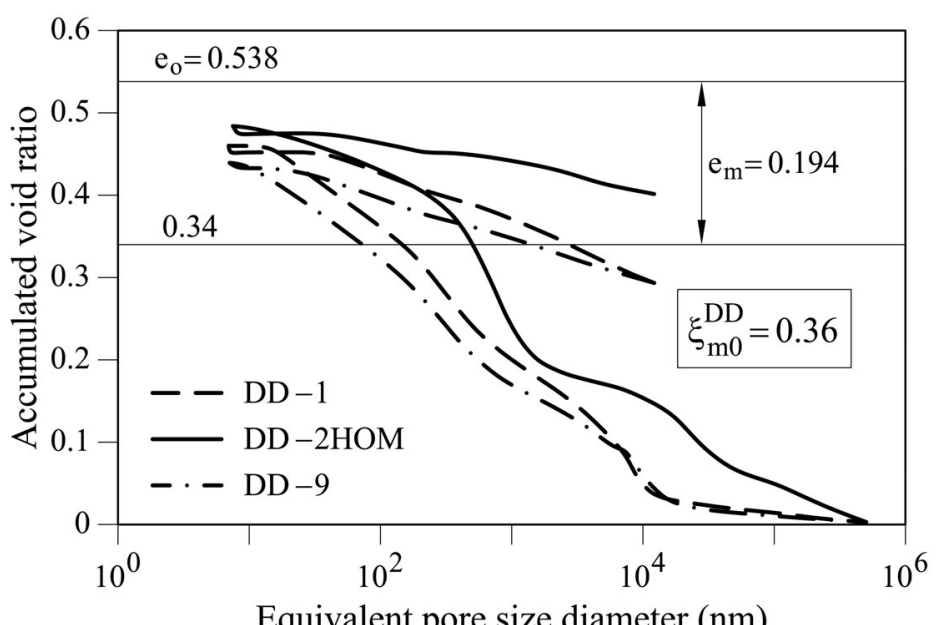

(a)

a)

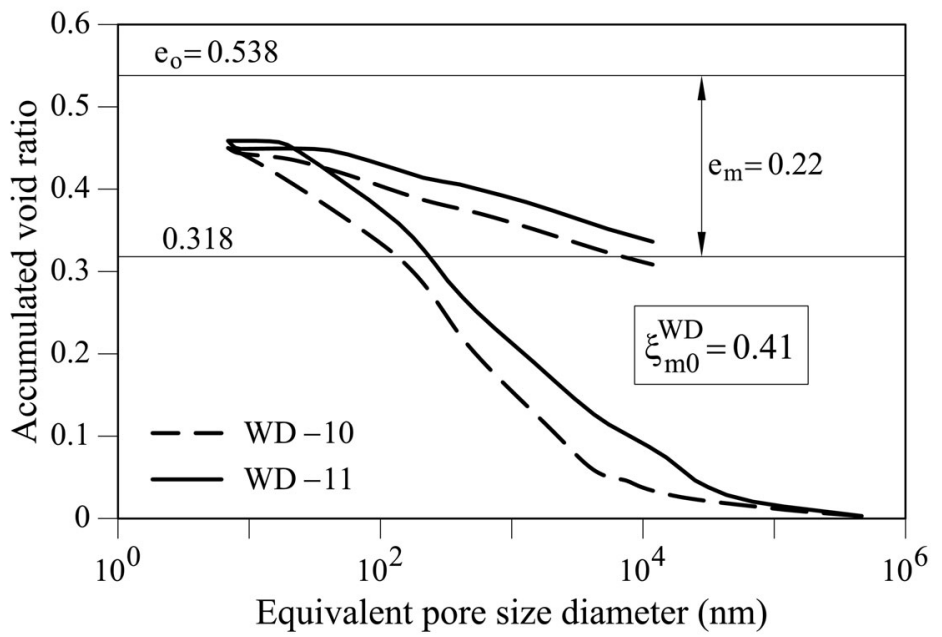

(b)

b)

Figure 22: MIP tests on compacted samples of Barcelona silty clay. a): DD samples; b): WD samples 


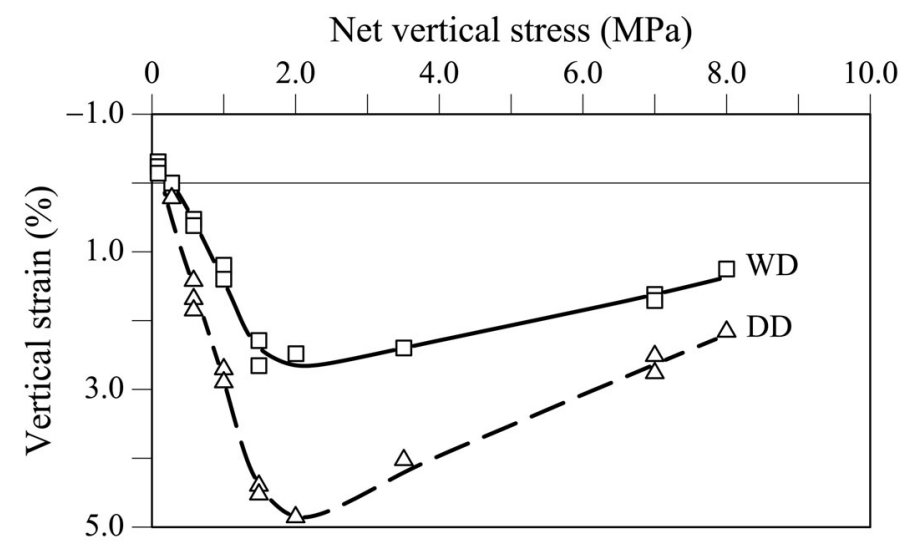

Figure 23: Measured collapse strains of samples WD and DD of compacted Barcelona silty clay in the range 0-8 MPa of confining total vertical stress.

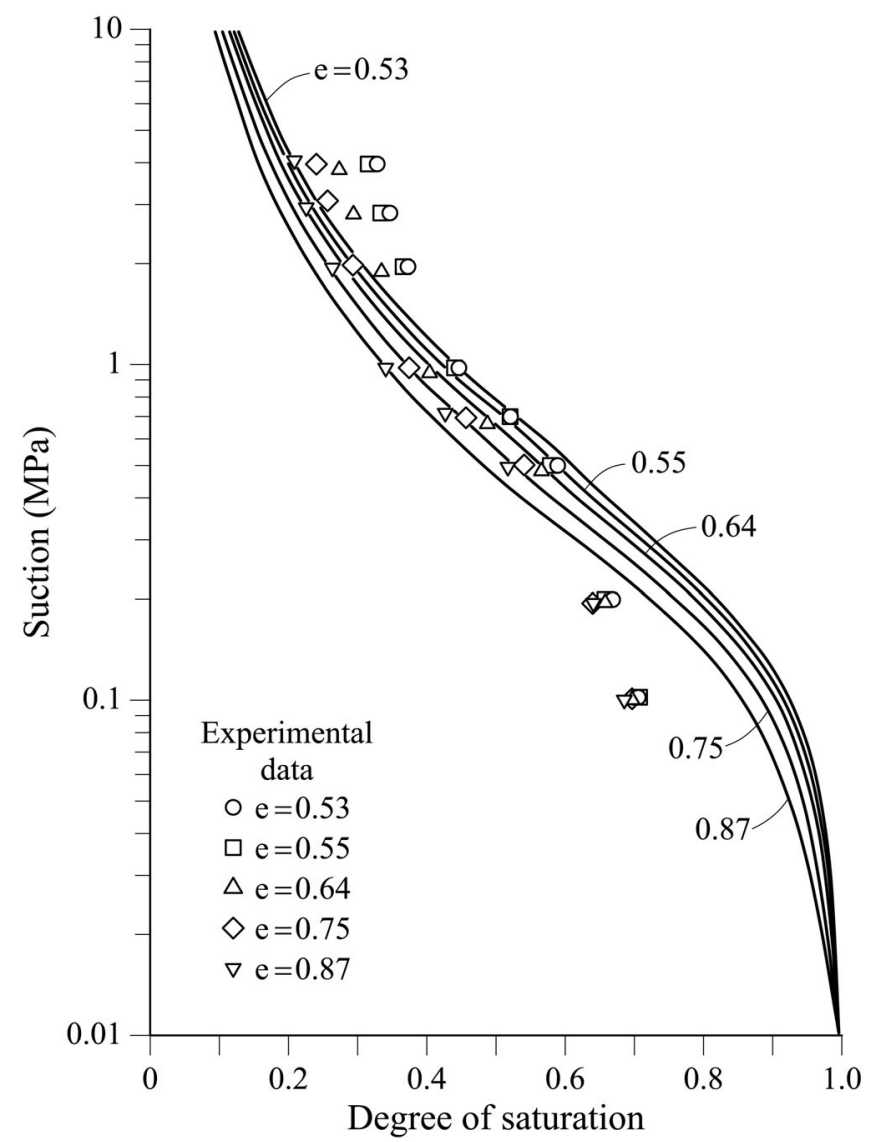

Figure 24: Water retention data on compacted Barcelona silty clay reported by Barrera (2002) and model (van Genuchten) approximations. 


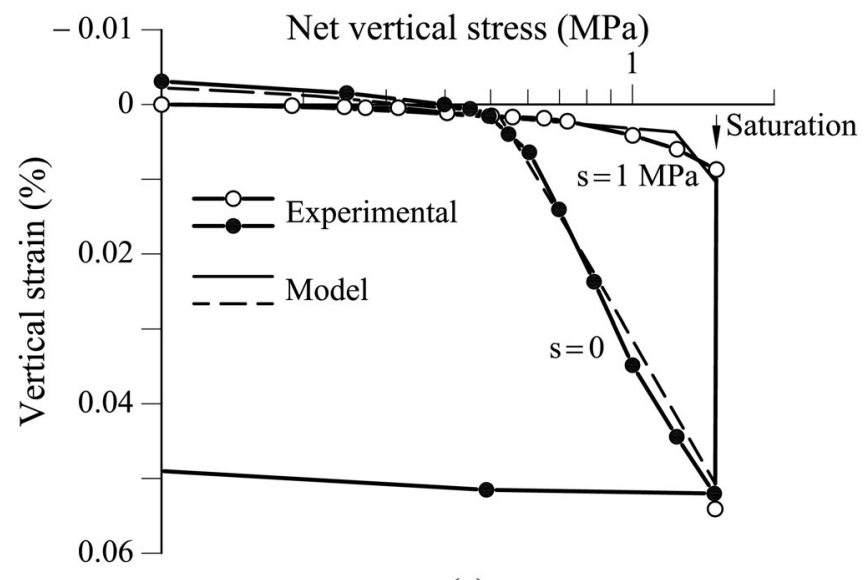

(a)

a)

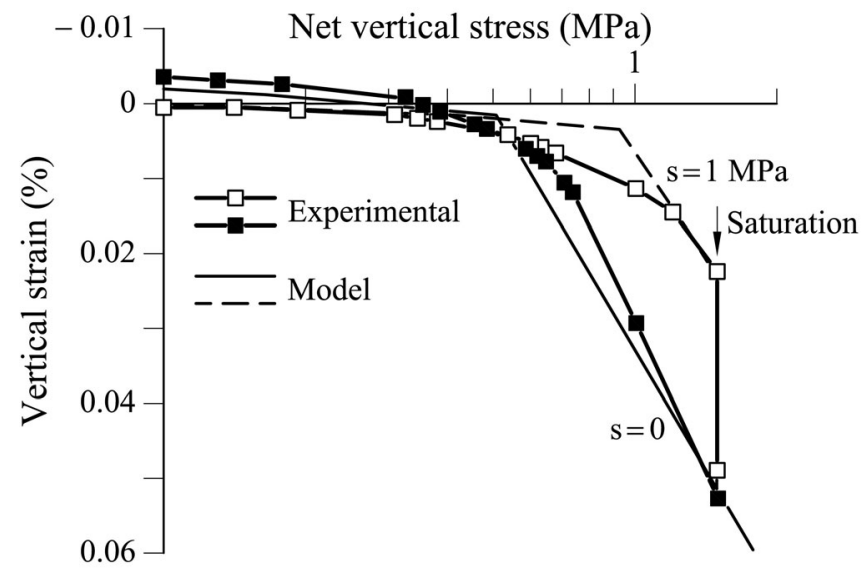

(b)

b)

Figure 25. Oedometric suction controlled $(s=1 \mathrm{MPa} ; s=0 \mathrm{MPa}$ ) compression curves of compacted Barcelona silty clay and model predictions. a) DD samples; b): WD samples. Results of a full wetting collapse test at a vertical stress of $1.5 \mathrm{MPa}$ are also indicated. 


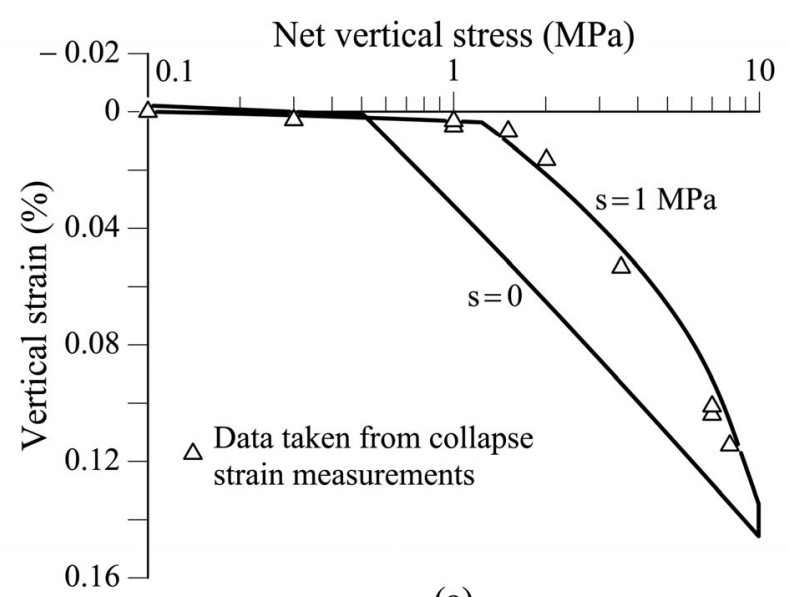

(a)

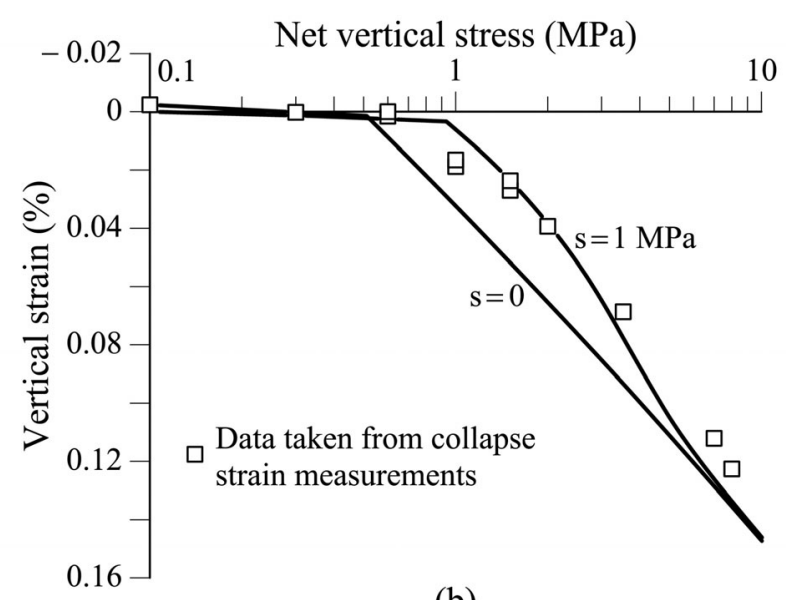

(b)

Figure 26: Estimated experimental compression curves of compacted Barcelona silty clay in the range 0-8 MPa of vertical stress and model predictions. a) Samples DD; b) Samples WD.

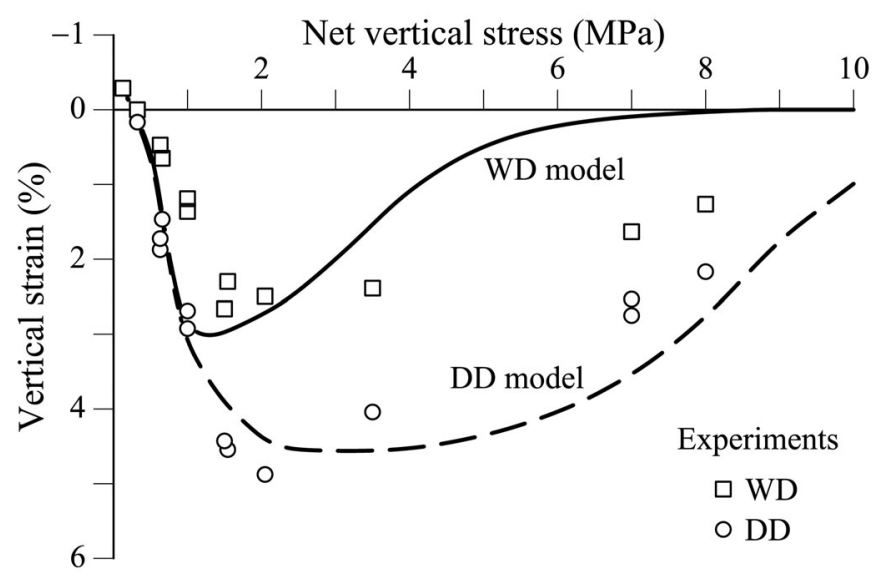

Figure 27: Measured and calculated collapse strains of samples DD and WD. 

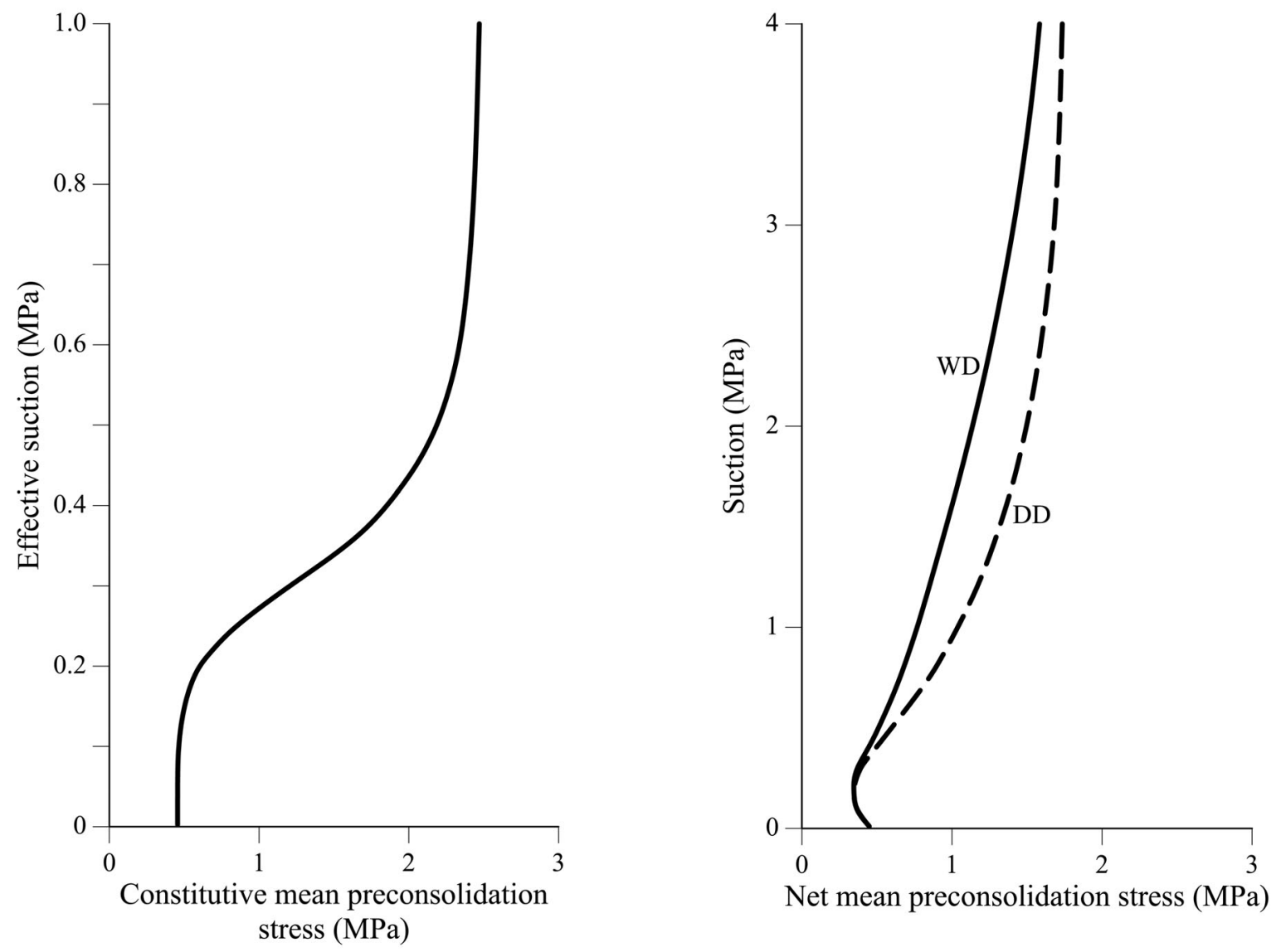

Figure 28: Initial LC yield curves of samples DD and WD. (a): In terms of constitutive stress and effective suction. (b): In terms of net stress and suction 